Tinbergen Institute Discussion Paper
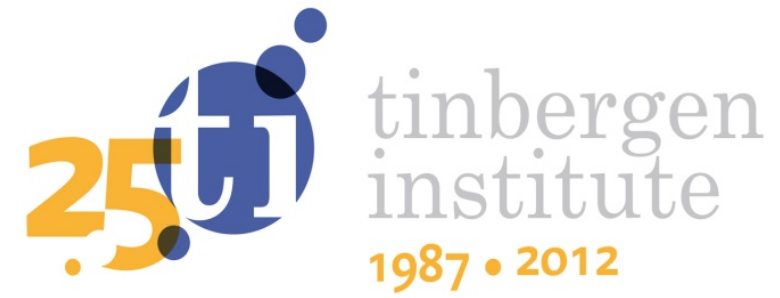

\title{
The Social Dilemma of Microinsurance: A Framed Field Experiment on Free- Riding and Coordination
}

Wendy Janssens

Berber Kramer

Faculty of Economics and Business Administration, VU University Amsterdam, and Tinbergen Institute. 
Tinbergen Institute is the graduate school and research institute in economics of Erasmus University Rotterdam, the University of Amsterdam and VU University Amsterdam.

More TI discussion papers can be downloaded at http://www.tinbergen.nl

Tinbergen Institute has two locations:

Tinbergen Institute Amsterdam

Gustav Mahlerplein 117

1082 MS Amsterdam

The Netherlands

Tel.: +31(0)205251600

Tinbergen Institute Rotterdam

Burg. Oudlaan 50

3062 PA Rotterdam

The Netherlands

Tel.: +31(0)10 4088900

Fax: $+31(0) 104089031$

Duisenberg school of finance is a collaboration of the Dutch financial sector and universities, with the ambition to support innovative research and offer top quality academic education in core areas of finance.

DSF research papers can be downloaded at: http://www.dsf.nl/

Duisenberg school of finance

Gustav Mahlerplein 117

1082 MS Amsterdam

The Netherlands

Tel.: +31(0)20 5258579 


\title{
The Social Dilemma of Microinsurance: Free-riding in a Framed Field Experiment
}

\author{
Wendy Janssens* and Berber Kramer ${ }^{\dagger}$
}

January 21, 2014

\begin{abstract}
Health shocks are among the most important unprotected risks for microfinance clients, but the take-up of micro health insurance typically remains limited. This paper attributes low enrollment rates to a social dilemma. Our theory is that in jointly liable groups, insurance is a public good. Clients can rely on contributions from group members to cope with shocks. Less risk averse clients have a private incentive to free-ride and forgo individual insurance even when insurance optimises group welfare. The binding nature of group insurance eliminates such free-riding. A framed public goods experiment with microcredit groups in Tanzania, eliciting demand for group versus individual microinsurance, yields substantial support for this hypothesis. This provides a potential explanation for low take-up rates.
\end{abstract}

JEL Codes: D71, I13, G21

Keywords: Health insurance, microfinance, risk-sharing, public goods experiment

\footnotetext{
*Tinbergen Institute, VU University Amsterdam, and Amsterdam Institute for International Development.

${ }^{\dagger}$ Corresponding author. Markets, Trade and Institutions Division, International Food Policy Research Institute; Tinbergen Institute; and VU University Amsterdam, b.kramer@cgiar.org. We gratefully acknowledge Tujijenge Tanzania and the PharmAccess Foundation for facilitating our research; Judith Lammers for her initial involvement; Stephen Kirama, Juda Lyamai, Swalehe Manture, Tumaniel Ngowi, Bernard Oyayo, Flaviana Piloty and Karen Rono from the University of Dar es Salaam for their dedication to the fieldwork; and the ILO microinsurance facility (grant no. 40070398), the Dutch Organization for Scientific Research (NWO grant no. 016.115.016), the C. Willems Stichting and the VU University Amsterdam, Faculty of Economics and Businsess Administration, for funding. We thank Chris Elbers, Jan Willem Gunning, Juan Camilo Cardenas, Glenn Harrison, Jose Luis Moraga-Gonzalez, Elisabeth Sadoulet, and Arthur Schram for their comments, as well as participants in a.o. the Pacific Development Conference (UC Davis 2012), CSAE (Oxford 2012), Midwest Economic Development Conference (Minneapolis 2012), NEUDC (Dartmouth College 2013), and seminars at the CREED University of Amsterdam, Erasmus University Rotterdam, Institute for Social Sciences, International Food Policy Research Institute (IFPRI), University of Bergen, University of California Berkeley, University of California Davis, University of Manchester, Tinbergen Institute and VU University Amsterdam.
} 


\section{Introduction}

Poor households in developing countries face tremendous risk but have limited access to formal insurance. Their vulnerability to shocks not only affects their immediate financial needs, but also undermines their ability to repay loans. To reduce default rates, microfinance is often offered to jointly liable groups (Aghion et al. 2000) 1. These groups share risk and contribute for members unable to repay, because access to future loans is conditioned on full group loan repayment. Contributions provide mutual but incomplete insurance, since the group will still default if too many members cannot repay. This paper argues that the take-up of formal insurance, covering the full risk, is hampered precisely because credit groups share part of the risk and can free-ride on others' contributions.

Illnesses and injuries are among the most important unprotected risks in developing countries (Gertler and Gruber, 2002), suggesting substantial scope for the introduction of formal health insurance. Nevertheless, enrollment in voluntary micro health insurance typically remains at low levels (e.g. De Allegri et al., 2009; Cole et al., 2013). We attribute low take-up to a social dilemma. Using non-cooperative game theory, we show that the decision to take individual health insurance in jointly liable credit groups is subject to free-riding. Even when group welfare is highest if all members enroll, less risk averse clients are tempted to forgo insurance, since fellow group members contribute to their loan repayment in case they fall ill. Only more risk averse clients will cooperate.

Empirically, free-riding is not a trivial outcome in a microcredit context. Microfinance groups are long-term relationships with repeated insurance decisions. The threat of future retaliation may well induce cooperative behavior (Bó, 2005). In addition, communication during regular group meetings, norms and social ties within credit groups may facilitate cooperation.

\footnotetext{
${ }^{1}$ Beyond this insurance function, group insurance also serves to reduce adverse selection and moral hazard, and enforce repayments (Ghatak and Guinnane 1999). Although major microfinance institutes have moved to individual liability, joint liability still features 26 and 20 percent of total loans in Africa and the rest of the developing world, respectively Beck and Cull 2013). Further, while individual liability reduces the probability of contributing (Giné and Karlan ming), individually liable clients may still operate as a group and support delinquent group members.
} 
We therefore test for free-riding in a framed field experiment (Harrison and List, 2004). In this experiment, 355 clients from a microfinance institution (MFI) in Dar es Salaam, Tanzania, played a public goods game resembling their decisionmaking context with joint liability. Depending on the treatment, participants were offered insurance at either the individual or group level. Group insurance requires a unanimous decision to enroll. Because a vote against insurance bars all peers from insurance as well, there are no opportunities to free-ride. We predict lower demand in the individual treatment, since less risk averse clients have a temptation to free-ride and opt out of individual insurance.

The experimental findings provide substantial evidence of this theory. Under group insurance, nearly all participants opt for insurance, including the less risk averse clients. Under individual insurance, the vast majority of more risk averse clients enrolls while a large number of less risk averse clients forgoes insurance. A significant share free-rides on contributions from their more risk averse peers, who consistently take insurance, and this client type is even less likely to enroll in insurance when paired with other less risk averse clients.

This study contributes to the existing literature in three distinctive ways. First, it highlights a crucial difference between individual and group health insurance schemes that is currently ignored in the literature. In a microfinance setting, restricting individual choice through group insurance does not only limit adverse selection, as has been widely investigated for employer-based insurance (Browne, 1992; McGuire, 2012), but also eliminates free-riding on others' contributions in case of a health shock. Our study hence provides an explanation for low take-up of individual health insurance in microcredit groups. This is relevant for numerous microinsurance programs struggling to increase enrollment.

Second, the experiment sheds light on the replicability of findings from conventional public goods games to the field. A large body of laboratory experiments with university students provides evidence of free-riding in artefactual games. Our game mimics real-life decisions for a population that differs from the usual participant in many respects (Cardenas and Carpenter, 2008), in a microcredit context 
where free-riding is not a trivial outcome. Thereby, we extend the experimental literature on the effect of joint liability on strategic investment behavior and moral hazard (e.g. Abbink et al., 2006; Cassar et al., 2007; Giné et al., 2010; Fischer, 2013). Unlike these papers, we take joint liability as the given contract structure, and study demand for group insurance versus individual insurance.

Third, we add to an emerging literature on the interactions between informal transfers and formal insurance. Independently, De Janvry et al. (2014) and Mobarak and Rosenzweig (2012) also refer to free-riding problems to explain low insurance take-up. De Janvry et al. focus on rainfall insurance in cooperatives, but do not test for free-riding empirically. Mobarak and Rosenzweig use observational data to investigate the interplay between informal risk-sharing in caste groups and formal insurance. Our key contribution is that we test for free-riding in a framed field experiment. In addition, we focus on insurance against idiosyncratic health shocks instead of co-variate weather shocks.

The remainder of this paper is structured as follows. The next section models the insurance decision in a jointly liable microcredit group and derives the freeriding hypothesis. Section 3 introduces the framed field experiment designed to test this prediction. Section 4 discusses participant characteristics, the risk aversion measure, and balancing across treatments. Section 5 analyses whether the insurance decision is subject to free-riding. The final section concludes.

\section{Theory}

\subsection{The game}

This section develops a model for the health insurance decision in jointly liable microcredit groups. A group of $N$ microcredit clients borrows money in every loan cycle $t \in\{1, \ldots, \infty\}$. Clients $i \in\{1, \ldots, N\}$ face idiosyncratic health risk. Ill clients incur health expenditures and cannot repay their share of the group loan. Fellow group members (henceforth peers) contribute for ill clients. However, if too many members fall ill, the group will default and the bank stops lending. Clients can 
take insurance to cover their health expenditures. This reduces both the need for contributions and the group default risk, making insurance a public good.

Figure 1 visualises this public goods game. In Panel (a), the left-hand block indicates a client's disposable income before contributing for peers, $\pi_{i t} \equiv \pi\left(H_{i t}, d_{i t}\right)$. Income depends on health $H_{i t} \in\{0,1\}$ and insurance status $d_{i t} \in\{0,1\}$, with $H_{i t}=1$ and $d_{i t}=1$ if and only if a client is healthy and insured, respectively.

Every loan cycle, a client invests her share of the group loan, $l$, yielding revenue $e+l$. Without insurance, $d_{i t}=0$, she repays and earns $\pi_{i t}=e$ if healthy, $H_{i t}=1$. However, prior to repayment, clients face IID health risk..$^{2}$ With probability $p$, a client is ill, $H_{i t}=0$, incurs catastrophic health expenditures $h \in(e, e+l]$, and cannot repay the loan. This so-called delinquent repays as much as she can, $l-(h-e)<l$, and has zero income, $\pi_{i t}=0$. Prior to every loan cycle, clients can enroll in insurance, covering health expenditures at an actuarially fair insurance premium $p h$. An insured client repays and has income $\pi_{i t}=e-p h$ irrespective of her health ${ }^{3}$ Earnings are sufficiently large to pay the premium, $e>p h$, and since clients have access to microcredit, we abstract from liquidity constraints.

The right-hand block of Figure 1 indicates a client's value after contributing for delinquent peers. Let the number of insured group members be $I_{t} \equiv \sum_{i}^{N} d_{i t}$. Since insured clients repay with certainty, the binomially distributed number of delinquents $F_{t}^{I_{t}}$ depends on the number of uninsured members, $N-I_{t}$, who fall ill:

$$
F_{t}^{I_{t}}=\sum_{i}^{N}\left(1-d_{i t}\right)\left(1-H_{i t}\right) \sim B\left(p, N-I_{t}\right) .
$$

Although clients contribute for delinquents, they do not fully share the risk. In order to repay the full group loan and continue borrowing, the group needs to jointly

\footnotetext{
${ }^{2}$ The model focuses on health risks that are typically covered by microinsurance, i.e. major injuries and acute illness. It does not focus on adverse selection (heterogeneity in $p$ ), epidemics (cross-sectional correlation) or chronic illness (serial correlation). Our theoretical results are robust to heterogeneous health risks for a wide range of parameters. The homogeneity in health risk can also be interpreted as assortative matching on health status.

${ }^{3}$ The model ignores income losses due to lower productivity or sickness absenteeism. The focus on expenditures does not qualitatively affect the theoretical predictions. Free-riding in individual insurance also occurs when there is background risk due to uninsured income losses. Although these losses reduce current as well as future earnings, and hence the dynamic incentives to enroll, full group enrollment will still optimise welfare for a subset of clients.
} 
contribute $h-e$ for each delinquent. Define $c_{i t} \equiv c\left(F_{t}^{I_{t}}, \pi\left(H_{i t}, d_{i t}\right)\right)$ as an individual's contribution for $F_{t}^{I_{t}}$ delinquents given her disposable income. If the total contribution is insufficient to contribute for all $F_{t}^{I_{t}}$ delinquents, $\sum_{i} c_{i t}<F_{t}^{I_{t}}(h-e)$, the group defaults. Clients contribute as much as they can (their income $\pi_{i t}$ ), the bank stops lending from period $t+1$ onwards, and clients derive zero value from both the present and all future loan cycles.

By contrast, if the group contribution is sufficient to repay, $\sum_{i} c_{i t} \geq F_{t}^{I_{t}}(h-e)$, lending continues. In loan cycle $t$, the client consumes current income net of contributions, $Y_{i t} \equiv \pi_{i t}-c_{i t}$, yielding utility $U\left(Y_{i t}\right)$. Further, because group lending continues, future loan cycles will also yield value. Total discounted expected utility from loan cycles $\{t+1, \ldots, \infty\}$ is summarised by the continuation value $V_{i, t+1}>0 \unlhd^{4}$ For ease of exposition, this section does not specify the continuation value and refers interested readers to Appendix A.

Regarding contributions $c(\cdot)$, the model makes four key assumptions:

(A1) A client never contributes more than her current income, $c_{i t} \leq \pi_{i t}$.

(A2) If $\sum_{i} \pi_{i t}<F_{t}^{I_{t}}(h-e)$, a client contributes her income, $c_{i t}=\pi_{i t}$.

(A3) If $\sum_{i} \pi_{i t} \geq F_{t}^{I_{t}}(h-e)$, the group repays the full loan, $\sum_{i} c_{i t}=F_{t}^{I_{t}}(h-e)$.

(A4) If $I_{t}(e-p h) \geq\left(N-I_{t}\right)(h-e)$ for all $I_{t} \geq I^{*}$, then $I^{*} \leq N-1$.

Assumption (A1) states that clients can only use current income to contribute for delinquent peers. Since delinquents themselves can only repay using their revenue net of health expenditures, $l+e-h$, own income and peers' contributions are the sole risk-coping tools. The model thus focuses on informal insurance from peers' contributions, abstracting from self-insurance strategies. This is consistent with survey evidence. A majority of our target population relies on financial support from others (32.3 percent) and own income (26.0 percent) to cope with illnesses and injuries. Substantially fewer use savings or sell assets (12.2 percent), or take additional loans from banks and MFIs (9.4 percent).

\footnotetext{
${ }^{4}$ Continuation has a strictly positive value for all clients because earnings within a round cannot be negative and have a positive expected value.
} 
Assumption (A2) says that in case total income in the group is insufficient to contribute for delinquent peers, clients contribute as much as they can, namely their current income $\pi_{i t}$. Such partial loan repayment is enforced to rule out the possibility of profitable strategic defaults. Indeed, in practice microfinance clients rarely default strategically, which can be explained by several factors (Armendariz and Morduch, 2010). Clients may for instance have compulsory savings with the bank, or fear pressure and harassment from loan officers.

Assumption (A3) means that when able to repay jointly, the group contributes the required amount for delinquents and repays the full loan. While we do not model a discretionary contribution decision, clients would have dynamic incentives to contribute a similar amount in a cooperative Nash equilibrium with voluntary contributions (Besley and Coate, 1995). 5

Assumption (A4) finally implies that the group can contribute for at least one delinquent. We define a threshold $I^{*}$ such that for all $I_{t} \geq I^{*}$, insured clients earn enough to contribute for $N-I_{t}$ uninsured peers: $I_{t}(e-p h) \geq\left(N-I_{t}\right)(h-e)$. This threshold satisfies $I^{*} \leq N-1$, meaning that $N-1$ insured clients can contribute for one uninsured group member. Groups hence share part of the risk.

\subsection{Risk preferences and beliefs}

Clients' risk preferences form the final building block. A client with absolute risk aversion $\theta_{i}$ is willing to join insurance if and only if this maximises expected utility over the present and all future loan cycles. Consuming $Y\left(H_{i t}, d_{i t}, F_{t}^{I_{t}}\right)$ in loan cycle $t$ yields time-separable utility $U\left(Y_{i t} ; \theta_{i}\right)$. Utility is increasing, $U^{\prime}(\cdot)>0$, concave, $U^{\prime \prime}(\cdot)<0$, and utility from zero earnings is normalised to zero, $U\left(0 ; \theta_{i}\right)=0$.

For tractability, the model assumes constant absolute risk aversion (CARA), so that $\theta_{i}$ does not depend on client $i$ 's wealth. This assumption is without loss of generality at $t=1$ when the new insurance product has not affected decisions yet. In later loan cycles, past insurance decisions may influence wealth, which in turn

\footnotetext{
${ }^{5}$ If peers jointly contribute $F_{t}^{I_{t}}(h-e)-c_{i t}$, and if the continuation value is sufficiently high, $V_{i, t+1} \geq c_{i t}$, client $i$ 's best response is to contribute the remaining $c_{i t}$ required to cover delinquents. Lower contributions result in group default and prevent continuation to the next loan cycle. By symmetry, contributing $c_{i t}$ is an equilibrium strategy for every client.
} 
will affect insurance decisions if the CARA property is violated.6.$^{6}$ our free-riding hypothesis is robust to the more flexible assumption of decreasing absolute risk aversion (DARA), as will be discussed in Section 2.4.

A threshold level of risk aversion $\theta^{*}$ exists such that a client with $\theta_{i}=\theta^{*}$ is indifferent between enrolling and not enrolling in a context without joint liability or dynamic incentives; in other words, is indifferent between risk-free earnings $e-p h$, and a gamble of earning $e$ only when healthy in a one-shot game:

$$
U\left(e-p h ; \theta^{*}\right)=(1-p) U\left(e ; \theta^{*}\right)
$$

Equation (2) defines two types of clients: more risk averse clients with a CARA coefficient $\theta_{i} \geq \theta^{*}$ (the 'high RA' type), who weakly prefer to enroll in a context without joint liability or dynamic incentives; and less risk averse clients with $\theta_{i}<$ $\theta^{*}$ (the 'low RA' type), who prefer not to enroll in this context.

Note that the low RA type has concave utility even though insurance is actuarially fair from the provider's perspective. Since health expenditures exceed earnings net of loan repayment, $h>e$, delinquents cannot fully repay their share of the loan, and one-time earnings with insurance are strictly below expected earnings without insurance, $e-p h<e(1-p)$. $^{7}$

When optimizing expected utility, clients take into account beliefs about the current and future number of insured peers and information on insurance decisions in the past. They have complete information on pay-offs and types, as well as perfect recall of peers' past health shocks and insurance decisions.

\subsection{Demand for group insurance versus individual insurance}

This section analyses demand for group versus individual insurance. Under both types of insurance, clients decide simultaneously and in private whether they want to enroll. The main difference is that under individual insurance, clients can join

\footnotetext{
${ }^{6}$ If income is fully consumed every period, wealth effects are absent. However, clients may save a portion of their earnings (as long as they do not use their savings to repay the loan), creating wealth effects.

${ }^{7}$ Insurance is hence not actuarially fair from a client perspective. Clients have limited liability because delinquents do not fully repay their loan. Delinquency is an externality either for the jointly liable group or the microfinance institution.
} 
insurance independent of peers' decisions, while group insurance requires unanimity. That is, group members cast anonymous votes indicating their willingness to join group insurance, and a group enrolls if and only if all $N$ clients prefer to enroll. Without unanimity, nobody enrolls nor pays the insurance premium.

Our main objective is to analyse whether individual insurance take-up is hampered by free-riding. This section therefore derives conditions under which full group enrollment optimises group welfare, while clients cannot commit to a full enrollment equilibrium under individual insurance. Since group insurance precludes free-riding, it can be used to identify whether full group enrollment is indeed the social optimum.

Group insurance (GI) We will first show that if all clients are willing to join group insurance, full group enrollment is socially optimal. Define $P_{0}$ as the probability that a group with zero insured members continues to the next loan cycle, i.e. the probability that the $N-F_{t}^{0}$ healthy group members' disposable income, $\left(N-F_{t}^{0}\right) e$, is sufficient to contribute the required $F_{t}^{0}(h-e)$ for $F_{t}^{0}$ delinquents:

$$
P_{0} \equiv P\left(F_{t}^{0} \leq N e / h\right)
$$

Insurance eliminates the default risk so that insured groups continue with certainty. The future benefits of full group enrollment over zero enrollment are therefore $V_{i, t+1}\left(1-P_{0}\right)$, where $V_{i, t+1}$ is the continuation value..$^{8}$

To analyse conditions under which clients are willing to join group insurance, let $d_{t}^{G I}\left(\theta_{i}\right)$ indicate client $i$ 's best response if she believes that all peers will vote for insurance in loan cycle $t$. The group will enroll if and only if this pivotal client votes for insurance. In that case, full group enrollment optimises group welfare.

PROPOSITION 1 (i) Under group insurance, $d_{t}^{G I}\left(\theta_{i}\right)=1$ if and only if

$$
\left.V_{i, t+1}\left(1-P_{0}\right) \geq \operatorname{E} U\left(H e-c\left(F^{0}, H e\right)\right) ; \theta_{i}\right)-U\left(e-p h ; \theta_{i}\right)
$$

\footnotetext{
${ }^{8}$ We assume that conditional on continuation, this value does not depend on past insurance decisions. Client $i$ 's vote will hence not affect the continuation value. Section 2.6 will discuss dynamic interactions.
} 


$$
\begin{gathered}
\text { (ii) If } d_{t}^{G I}\left(\theta_{i}\right)=1 \forall i \in\{1, \ldots, N\} \text {, then } \\
\sum_{i} U\left(e-p h ; \theta_{i}\right) \geq \sum_{i} \mathrm{E}\left[U\left(Y_{i t} ; \theta_{i}\right) \mid I_{t} \in\left[I^{*}, N-1\right]\right],
\end{gathered}
$$

Appendix $\mathrm{B}$ proves the proposition. In words, the pivotal voter prefers to enroll if and only if the future benefits of full group enrollment, $V_{i, t+1}\left(1-P_{0}\right)$, outweigh the period- $t$ utility cost of taking insurance. If this condition is satisfied, and all group members are willing to join when pivotal, full group enrollment enhances group welfare over an outcome with $I^{*} \leq I_{t} \leq N-1$ insured members (Equation 5). When $I_{t} \geq I^{*}$, a group can always repay the loan. Uninsured clients then expect higher earnings compared to full enrollment, but insured clients' contributions to their loan repayment reduce total expected group earnings by an equal amount. Therefore, clients with concave utility prefer the risk-free option.

Combined with clients' revealed preference for full enrollment over zero enrollment, full group enrollment will be the social optimum if all clients vote for insurance. Since a vote against insurance would bar all peers from insurance, clients cannot free-ride on contributions from insured peers by opting out of insurance individually, and they will commit to the social optimum.

Individual insurance A next question is whether individual insurance is subject to free-riding. We analyse whether clients strategically forgo individual insurance in a pure strategy Nash equilibrium, even though insurance optimises group welfare. Many mixed strategies and other possible equilibria exist, but our aim is to show whether free-riding may occur; not to provide a full listing of all equilibria.

Denote $d_{t}^{I I}\left(\theta_{i}\right)$ as client $i$ 's best response in period $t$ if she believes that all peers will enroll in individual insurance. We will analyse the conditions under which a client with such beliefs will not take insurance, $d_{t}^{I I}\left(\theta_{i}\right)=0$. This allows us to identify free-riding, unconfounded by uncertainty about peers' decisions or coordination failures. The next proposition states when such free-riding occurs.

PROPOSITION 2 Under individual insurance, $d_{t}^{I I}\left(\theta_{i}\right)=1$ if $\theta_{i} \geq \theta^{*}$, and $d_{t}^{I I}\left(\theta_{i}\right)=$ 
0 if $\theta_{i}<\theta^{*}$, where $\theta^{*}$ is defined by Equation (2).

Appendix $\mathrm{B}$ provides a proof. Intuitively, if all $N-1$ peers enroll, the group can repay the loan by Assumption (A4), and peers contribute irrespective of a client's own insurance decision by Assumption (A3). A client hence faces a trade-off between the one-time risk-free insurance option and a gamble with higher but uncertain earnings, as in a context without joint liability and dynamic incentives. Definition (2) implies that only high RA clients with $\theta_{i} \geq \theta^{*}$ will enroll in this context. Free-riding hence occurs only among the low RA type.

\subsection{Hypotheses for different client types}

The propositions above yield two testable predictions. On the one hand, high RA clients are not tempted to free-ride under individual insurance. Hence, if all members of a group are of the high RA type and believe that their peers will enroll, they will all enroll and commit to the social optimum. Assuming that clients know they have only high RA peers, whose best response is $d_{t}^{I I}=1$, we expect limited coordination failures in these groups 9 We therefore predict equal demand for group insurance and individual insurance in groups with only high RA members:

HYPOTHESIS 1 For client $H$ with $\theta_{H} \geq \theta^{*}$ and only high RA peers,

$$
\mathrm{E}\left[d_{t}^{G I}\left(\theta_{H}\right)-d_{t}^{I I}\left(\theta_{H}\right)\right]=0
$$

A rejection of this hypothesis in early loan cycles only, when clients may be uncertain about peers' actions, could imply a coordination problem.

On the other hand, low RA clients with only high RA peers will forgo individual insurance even if they believe that all their peers will enroll, and even if they prefer to join when offered group insurance. The second hypothesis tested in the

\footnotetext{
${ }^{9}$ The coordination problem can also be interpreted as a case of background risk. Purchasing insurance increases the probability of having to contribute for uninsured ill peers, which reduces demand. So far, the literature has attributed low demand to other types of background risk, for instance limited credibility of the insurance provider (Dercon et al. 2011), or basis risk in index-based weather insurance products (Cole et al. 2013).
} 
experiment is therefore that low RA clients with only high RA peers have higher demand for group insurance than for individual insurance:

HYPOTHESIS 2 For client L with $\theta_{L}<\theta^{*}$ and only high RA peers,

$$
\mathrm{E}\left[d_{t}^{G I}\left(\theta_{L}\right)-d_{t}^{I I}\left(\theta_{L}\right)\right]>0
$$

We will compare the demand for group and individual insurance within two additional subsamples. First, we focus on high RA clients with at least one low RA client in the group. Propositions 1 and 2 translate into Hypothesis 2 only if low RA clients believe that all their high RA peers will join individual insurance. This is not trivial. Appendix C shows that given the parameters in the experiment, high RA clients' willingness to join individual insurance decreases in the number of uninsured peers. We will thus test whether low RA clients' belief concerning their peers' cooperative behavior is warranted.

Second, since groups may in practice sort on risk attitudes (Genicot and Ray, 2003; Attanasio et al., 2012), we will analyse decisions of low RA clients with at least one other low RA peer. Appendix C shows that their best response may go either way, depending on the continuation value. If it is sufficiently high, low RA clients with uninsured peers will decide to enroll in order to reduce the group default risk. An empirical question is hence whether the difference in demand between group and individual insurance becomes more pronounced if a group has a larger fraction of low RA members; in other words, whether assortative matching would magnify the social dilemma among low RA clients.

\subsection{Time dynamics}

Thus far, the analysis did not consider dynamics across loan cycles. This section discusses four dynamic mechanisms and their implications for our hypotheses.

First, wealth accumulated in past loan cycles affects future insurance demand if clients do not have constant absolute risk aversion. Assuming decreasing absolute risk aversion (DARA), high RA clients become less risk averse as their 
wealth increases. Ultimately, their absolute risk aversion can reduce to $\theta_{i}<\theta^{*}$. A formerly high RA client may hence become a free-rider in later loan cycles. This reduces demand for individual insurance relative to group insurance.

Second, differential default rates in early loan cycles may affect average demand for group versus individual insurance in subsequent loan cycles. Clients unwilling to join bar their peers from enrolling in group insurance, but not from individual insurance. This increases the relative default risk under group insurance. Over time, selective attrition can increase the observed difference in demand between group insurance and individual insurance.

Third, peers' types and strategies may become more salient over time. Clients can update their beliefs after observing their peers' insurance decisions in the first loan cycle. Such learning effects create focal points and reduce any coordination problems in high RA groups without free-riding peers. By contrast, in mixed groups, low RA clients with insured high RA peers become reinforced in their belief that they can free-ride without risking a group default, and enrolled clients might respond to free-riding by forgoing insurance themselves. This will increase the difference in demand between group and individual insurance over time.

In sum, time dynamics will affect the difference in demand for group insurance and individual insurance in several ways. In groups with only high RA members, wealth effects may reduce the demand for individual insurance, whereas updated beliefs on peers' strategies may instead solve any coordination failures and increase demand. In groups with low RA clients, dynamic mechanisms will further reduce the willingness to take individual insurance, reinforcing Hypothesis 2.

\subsection{Conditional cooperation and social interaction}

Although we theoretically predict free-riding among low RA clients, it is not trivial that our hypotheses hold empirically. In a microfinance setting, group membership is a long-term commitment. Groups borrow often increasing amounts conditional on prior loan repayments, and switching groups is costly. Clients will

hence face repeated insurance decisions within the same group, and they might 
sanction free-riders by staying uninsured themselves in future loan cycles. ${ }^{10}$ Conventional laboratory experiments indeed find that dynamic interactions enhance cooperation (Bó, 2005). Appendix C shows that given the parameters used in our experiment, the strategy to stay uninsured in future loan cycles as a sanction on free-riding is both a credible threat and prevents free-riding.

Further, microfinance institutions teach their clients to be 'good borrowers' (Armendariz and Morduch, 2010), which may shape norms to enroll in insurance, and microfinance clients meet regularly to repay their loans. Communication during these meetings may enhance cooperation (Sally, 1995), for instance because individuals perceive a cost of lying or feel guilt from blame (Battigalli and Dufwenberg, 2007; Vanberg, 2008, Charness and Dufwenberg, 2011). This result will be strongest in groups with close social ties (Cassar et al., 2007). Norms, communication and social ties may also shape beliefs and increase knowledge of peers' types and strategies, enhancing coordination.

\section{Method}

\subsection{Design}

To test the free-riding mechanism, we conducted a framed field experiment with 355 clients from a microfinance institution (MFI) in Dar es Salaam, Tanzania. Participants first played a basic microinsurance game to measure their risk aversion type. A second game elicited their demand for either group or individual insurance. This public goods game framed the insurance decision in the context of a jointly liable microcredit group, and resembled the model described in Section 2 .

For participants used to group lending, the microcredit frame may have triggered different norms and behavior compared to an abstract public goods game. This is a key advantage of a framed field experiment over conventional laboratory experiments with student populations. The field laboratory still offers a controlled

\footnotetext{
${ }^{10}$ Alternatively, clients could exert direct social pressure. Fehr and Gächter 2000, show that individuals are willing to punish their peers even if this is costly. We allow for retaliation through future decisions. Immediate sanctions are left for future research.
} 
setting without confounding distortions from e.g. initial beliefs, health and social capital. Further, participants faced significant monetary incentives based on their decisions during the games, which is commonly assumed to elicit more accurate responses than hypothetical survey questions (Holt and Laury, 2002).

At the same time, the high degree of control in the laboratory goes hand-inhand with an abstraction from other mechanisms that drive insurance decisions. Although the main game resembled group-based lending as closely as possible, the demand for microinsurance in jointly liable credit groups depends on more factors than can be studied simultaneously in a game. The concluding section discusses a number of mechanisms to consider when interpreting our experimental findings outside the laboratory.

\subsubsection{Game 1: Measure for risk aversion}

Participants first played an individual insurance game without joint liability or dynamic incentives. Panel (b) of Figure 1 represents this introductory lottery, showing exactly the same game as Panel (a), but now with the specific values used in the experiment. Again, the left-hand side indicates earnings before contributing for delinquent peers, and the right-hand side presents expected utility.

A participant borrowed $l \equiv 40,000$ Tanzanian Shillings (TZS; 26.67 USD) and fell ill with probability $p \equiv 1 / 5$. Without insurance, healthy participants were able to repay their loan, and earned $e \equiv 22,500$ after loan repayment. Ill participants incurred health expenditures that fully absorbed earnings before loan repayment; $h \equiv e+l=62,500$. As a result, they did not repay their loan and received nothing, $\pi_{i t}=0$. An insured player paid the insurance premium, repaid the loan, and received $e-p h=10,000$ with certainty.

In this first game, the participant hence faced a trade-off between lower riskfree earnings versus higher but risky earnings.11 By Definition (2), a client has

\footnotetext{
${ }^{11}$ To enhance understanding of the dynamic incentives, a participant played two rounds of this game and moved to the second round only if she repaid the first loan. Dynamic incentives were absent in the second round. The risk aversion measure uses decisions in this last round, assuming that uninsured individuals who defaulted in the first round would again have forgone insurance. Using first- instead of second-round decisions yields similar results.
} 
high risk aversion, $\theta_{i} \geq \theta^{*}$, if and only if she enrolled. Because there was no joint liability, our measure reflects risk attitudes rather than social preferences or beliefs about peers' decisions. Risk aversion was not separated from a certainty or framing effect, but the first-game decision is sufficient to separate the two theoretical client types, i.e. high RA and low RA clients, with qualitatively different predictions in a context of individual insurance, joint liability and dynamic incentives.

\subsubsection{Game 2: Group versus individual insurance}

Next, in groups of $N=5$ clients, participants played a microinsurance game with joint liability and dynamic incentives, as represented in the right-hand side of Panel (b). Following the theoretical framework, group members contributed for delinquent peers who could not repay their share of the loan, and defaulting groups did not continue to the next loan cycle ${ }^{12}$

Note that in the experiment, a group could contribute for at most one delinquent, so that $I^{*}=N-1=4$, a special case of Assumption (A4). If one group member could not repay, her four repaying peers (both insured and uninsured) each contributed 10,000. The group loan was fully repaid and the group continued to the next loan cycle. If more than one group member could not repay, the remaining group members' disposable income was at most three times 22,500, which was insufficient to contribute the 80,000 required for two delinquents. In that case, the group defaulted and repayed as much as it could afford. After contributing, profits were zero for all members and the game ended.

Similar to Cassar et al. (2007), participants were told that they would play the game for a large, unknown number of rounds to avoid a last round effect. Thus, participants only knew they would play as long as they repaid their loan; they did not know when the game would end. The experimenter announced an exogenous

\footnotetext{
${ }^{12}$ Parameters were selected as follows. First, the actuarially fair insurance premium had to be of the same order of magnitude as the insurance premium for a policy that the MFI was contemplating to introduce, fixing the insurance premium at $p h=12,500$. Second, a health shock probability of $p=1 / 5$ made the health risk salient (on average, one group member would be ill per round), and determined catastrophic health expenditures $h=12,500 / p=62,500$. To simplify the experimental instructions, these health expenditures fully absorbed earnings before loan repayment, so that $h=e+l=62,500$. Finally, in groups with $N=5$ clients, by Asssumption (A4), 4 insured clients needed suffiient earnings to contribute for 1 uninsured client, $4(e-12,500) \geq 62,500-e$, so that $e \geq 22,500$ and $l=h-e \leq 40,000$.
} 
termination shock upon completion of the fourth round. From then on, one group member tossed a die after every round. If the die landed at 1 , the game ended for the group. ${ }^{13}$ Or, as stated by one of the participants (based on transcripts from participants' communication during the games):

"I congratulate our sister for throwing another number than one, which enables us to play this round. That means the game goes on and our earnings increase as well."

At the start of the experiment, every participant received a symbol that she was asked not to reveal to others. Participants learned about the insurance decision and health status of the other symbols in their group, i.e. their peers. This information was revealed after every round, also after the first game used to elicit risk aversion. Hence, participants knew the types of their peers and could update their beliefs about peers' actions. The identification through anonymous symbols limited the effects of future outside interactions on behavior in the game.

In this second game with joint liability, treatments varied in two dimensions. First, depending on the treatment, participants were offered either group insurance (GI) or individual insurance (II). The group insurance treatment revealed whether individuals prefer full over zero enrollment in a context with joint liability. ${ }^{14}$ Group insurance provides a benchmark for optimal demand, and lower demand under individual insurance indicates a social dilemma.

The experiment also varied the possibility to communicate. In treatments without communication (II-NC and GI-NC), clients did not talk to other participants. In the communication treatments (II-C and GI-C), group members talked for two minutes preceding every round. This served to identify whether verbal interactions, inevitably occurring in real life and potentially easier to implement than binding group insurance schemes, limit free-riding. Assistants tape-recorded, transcribed and translated communication to English.

\footnotetext{
${ }^{13}$ Because of time constraints, clients played at most six rounds, but they were not informed of this beforehand.

${ }^{14}$ Alternative treatments such as mandatory insurance and individual liability would have been unable to verify this key assumption. In the former alternative, clients cannot reveal their preference, and in the the latter, insurance is valued differently as there is no risk-sharing within the group.
} 


\begin{tabular}{lccc}
\hline \hline & Individual Insurance & & Group Insurance \\
\hline No Communication & II-NC & $\Leftrightarrow$ & GI-NC \\
& $N=75$ (3 sessions) & & $N=90$ (4 sessions) \\
Communication & II-C & $\Leftrightarrow$ & GI-C \\
& $N=75$ (3 sessions) & & $N=115$ (4 sessions) \\
\hline \hline
\end{tabular}

Treatments varied by session. On average, 25 clients participated in a session. Each client participated in only one session, and hence one treatment, to avoid order effects. The table above presents the number of participants and sessions by treatment. We organised fourteen sessions in total, six with individual insurance and eight with group insurance, and half of these included communication.

\subsection{Procedures}

Sessions were organised near clients' houses or businesses in eight different areas of Dar es Salaam, in venues where credit groups typically meet with their loan officers for weekly repayment. Clients were invited to come to one of the sessions in their area, which were introduced as interactive seminars for a research project on health insurance. They could bring along credit group members. Every treatment was played at most once in an area and treatments were not announced during mobilization. Clients knew that only members of their MFI would participate and that the research was independent of the MFI, to assure confidentiality.

A session lasted approximately 3 hours. First, assistants administered a short questionnaire on participants' socio-demographics, health and credit group-related characteristics. Three games were then played: (1) the first game with both insurance and lending at the individual level to elicit a measure for risk aversion including a practice round; (2) the same game but with a higher insurance premium of 17,500 TSH, compared to the standard premium of 12,500 TSH, which served as a robustness check; and (3) the main game with joint liability and dynamic incentives eliciting demand for either group or individual insurance - also 
preceded by a practice round ${ }^{15}$

Participants received their earnings after every round. This made the game easier to comprehend. We stored earnings in closed boxes (piggybanks) until the end of the session, so that prior earnings could not be used to repay future loans; this will also have induced bracketing, or evaluating, earnings by round rather than in terms of cumulative outcomes. At the same time, this procedure may have created wealth effects. The empirical analyses will therefore focus on decisions in the first round. We will be cautious when interpreting decisions in later rounds, since these are influenced by wealth effects and other dynamic mechanisms as discussed in Section $2.5^{16}$

Experiments commonly avoid wealth effects by randomly selecting one of the rounds for payment, which is valid under the assumption that choices satisfy the independence axiom (Holt and Laury, 2002). However, prominent theories such as rank-dependent utility (Quiggin, 1982) and cumulative prospect theory (Tversky and Kahneman, 1992) violate this axiom. Further, participants may update their beliefs about their peers' strategies and better understand the financial implications of their own decisions every time they receive earnings (Harrison and Swarthout, 2012). Hence, while we do acknowledge the limitations of our payment mechanism, randomly selecting one round also has its shortcomings (Cox et al., 2011).

Clients received a show-up fee of 7,000 TZS (US \$ 4.67) and could earn in addition up to 27,500 TZS (US $\$ 18.35$ ). For every 10,000 earned in the game, a participant received 1,000 TZS. The average participant earned 18,000 TZS (US $\$ 12$ ), approximately 2.5 days of business profit. These are significant stakes that will have induced concave rather than linear utility.

\footnotetext{
${ }^{15}$ See Appendix $D$ for an English translation of the Kiswahili instructions.

${ }^{16}$ We could control for wealth effects using an instrumental variable approach, instrumenting wealth with prior (random) health shocks. We decided not to do so since health shocks are also correlated with subsequent attrition.
} 


\section{Data}

\subsection{Study population and participant characteristics}

The microfinance games were played by clients of Tujijenge Tanzania Ltd, an MFI providing microcredit in Dar es Salaam since 2006. Tujijenge currently has approximately 12,800 members engaged in group lending schemes. The average loan size is 450,000 Tanzanian Shillings (US \$ 300) and clients pay 12 percent interest per loan cycle of three months. Groups of five to seven members are jointly liable for repayment. They formulate by-laws such as fines for not repaying ("delinquency") in their weekly meetings.

Columns (1) and (2) in Table 1 describe the main characteristics of the 355 participants in the games. Panel A summarises demographic and socio-economic characteristics. As is common in MFIs, the majority of our participants was female. Participants were on average 36 years old and 76.1 percent was married. The average participant had 5.1 household members and had completed around 7 years of education, corresponding to primary school. Monthly per capita income was on average 84,400 TZS (US \$ 54).

Panel B describes the population in terms of health characteristics. Just more than half (54.9 percent) of the participants consulted a health care provider in the past three months, and for 73.5 percent, at least one other household member did so. Health expenditures during that same period, averaged over all household members, were 43,000 TZS, or 8,300 TZS (US \$ 5) per capita. This was 9.9 percent of monthly per capita income. In the past three months, the event that a household member needed health care but did not receive it due to a lack of money occurred on average 0.6 times. Finally, although 41.1 percent of the participants knew what health insurance is, only 7.3 percent were enrolled; mainly because insurance is virtually inaccessible for workers outside the formal sector.

Panel $\mathrm{C}$ presents credit-related variables. The average monthly business profit was TZS 226,000 (US \$ 145) and represented a considerable proportion of total household income. The average participant had been a member of Tujijenge for a 
little more than one year, and eleven percent of participants were waiting to take out their next loan. Approximately one third indicated that at least one member of their credit group defaulted during a meeting in the past three months. Respondents contributed for almost all delinquents. Among respondents who failed to repay themselves, a much lower percentage reported that group members contributed. Participants were either more supportive to their group members than non-participants, or gave socially desirable answers to these sensitive questions.

The last variable examines the social ties between group members in the games. Within sessions, participants were randomly assigned to groups. On average, 0.5 of their game group members were also a member of their real credit group. Preexisting social ties could potentially affect enrollment decisions through trust, cooperation and beliefs. We will exploit random variation in the number of real group members to check whether social ties enhance cooperation.

Column (3) compares our sample to a representative survey among 407 Tujijenge clients conducted three months before the microfinance games. The columns presents the population averages based on this survey and stars indicate the $p$ value from a $t$-test for equal means in these two non-overlapping samples.

Game participants were more likely to be female, had larger households, less education and were less likely to be insured than the average Tujijenge member. Participants were also twice as likely to have visited a health provider in the past three months. This could have been due to an explosion in a munition depot near one of the study areas just prior to the games. This accident caused injuries for a substantial proportion of households in surrounding areas.

The sample of participants does not perfectly resemble the respondents in the representative survey. As is common in framed field experiments, microfinance clients would only attend a session when interested. Further, the survey was conducted three months earlier, and may have included clients who had dropped out of the group by the time of the experiment, as well as inactive clients from the MFI's register. This should be kept in mind when interpreting the results. 


\subsection{Risk aversion}

Panel D summarises the measure of risk aversion. Using the first game without joint liability and dynamic incentives, we classify 25.6 percent of the participants as the low RA type, and 74.4 percent as the high RA type. This suggests relatively risk averse decisions compared to those in conventional risk lotteries. Framing the lottery as an insurance decision may have induced loss-averse behavior or a preference for certainty. This does not confound our identification strategy, which only requires that first-game decisions predict second-game equilibrium strategies.

Due to time constraints within sessions, we did not play standard Binswanger or Holt and Laury risk lotteries. To validate our measure, Columns (5) to (8) present a Probit model for low risk aversion as a function of participants' characteristics. Columns (7) and (8) only include variables common to both the representative survey and the questionnaire administered during the experiment.

Consistent with our expectations, women as well as participants with higher household health expenditures are more risk averse, although the coefficient for the first variable is not statistically significant in the full model. Participants from larger households, who have more opportunities for intra-household risk-sharing, and those with health insurance are less risk averse. The latter finding is most likely due to a wealth effect. In the absence of microinsurance, only formally employed households have access to insurance.

Risk aversion increases with the number of membership years and with having an outstanding loan. People in debt might be more risk averse. None of the delinquency and contribution variables in Panel $\mathrm{C}$ is significant, suggesting that our risk aversion measure is uncorrelated with social preferences or 'good borrower behavior', and rather measures preferences towards risk in private earnings.

The extent of free-riding depends on the target group's risk profile. Our theory predicts that the social dilemma will be more pronounced in target groups with a large proportion of low RA individuals. The model in Columns (7) and (8) predicts out-of-sample that 30.7 percent of the target group has low risk aversion. This is slightly higher than the 25.6 percent in the participant sample. Our results 
will therefore represent a lower bound for the level of free-riding in the population. The difference in the proportion of clients with low risk aversion is however not significant. Standard errors calculated by means of the Delta method yield a 95 percent confidence interval equal to $[23.3,38.2]$.

\subsection{Balance of characteristics over treatments}

To examine the comparability of treatment groups, Table 2 compares the characteristics of participants in group insurance versus individual insurance sessions. The first two columns compare high RA participants under individual and group insurance. The next two columns restrict the sample to low RA participants. Standard errors are clustered at the session level. Due to a relatively small number of 14 sessions, the table presents the two-sided $t$-percentile in a clustered wild bootstrap. This procedure will be used for all subsequent regression analyses. Cameron et al. (2008) show that the wild bootstrap improves inference even when there are as few as five clusters and that this generalises to cases where the dependent variable is binary instead of continuous ${ }^{17}$

The assignment to treatments has resulted in relatively comparable treatment groups (Panels A - C). Only a few characteristics are not well balanced between group insurance and individual insurance sessions. High RA participants are more likely to know about and be enrolled in health insurance in the individual insurance treatment. For low RA participants, there are no statistically significant differences, but this might also be due to a lower sample size. Since balancing is not perfect, the analyses will control for all variables that are significantly correlated with demand for insurance, regardless of their significance in Table 2, as suggested in Bruhn and McKenzie (2009). The main results are not sensitive to the in- or exclusion of omitted unbalanced characteristics.

The risk types are well-balanced across treatments. In the group insurance treatment, 26.3 percent of participants are of the low RA type, versus 24.7 percent in the individual insurance treatment $(p=0.722)$. However, some of the game-

\footnotetext{
${ }^{17}$ The bootstrap procedure imposes $\beta_{I I}=0$ and uses Rademacher weights for the residuals.
} 
related variables in Panel D vary across treatments. In particular, for low RA participants, the number of low RA peers is lower under individual insurance. The regressions will control for this variable. Further, health shocks are random in the games and occur for around 20 percent of the observations as predicted by the law of large numbers. Nonetheless, their incidence is not perfectly balanced. Analyses of first-round decisions will control for the proportion of ill rounds in the risk aversion game, and regressions using subsequent rounds will control for the proportion of ill rounds in both the risk aversion and joint liability game.

\section{Results}

This section presents the experimental findings. The main outcome of interest is a participant's willingness to join insurance - henceforth called demand. Under group insurance, demand is derived from the individual votes. These votes reveal whether participants have a preference for full over zero enrollment when there are no opportunities to free-ride. The experiment tests whether demand is lower in the individual insurance sessions.

We will first use a basic model to compare average demand for group versus individual insurance in the first round. This is followed by a model that distinguishes between clients with and without low RA peers. These analyses directly test the two theoretical hypotheses. Next, we estimate our model without and with communication, and conclude by analyzing decisions in later rounds.

\subsection{Basic model}

The analysis starts with a non-parametric analysis, treating every session as one observation and using a one-sided Mann-Whitney test to examine whether individual insurance sessions rank lower in terms of average demand compared to group insurance sessions ${ }^{18}$ Figure 2 presents the demand for health insurance in the first round. The figure shows the percentage of participants in each session

\footnotetext{
${ }^{18}$ We use exact rather than asymptotic test statistics because of the limited number of sessions.
} 
willing to join group insurance (the circles on the left-hand side) or individual insurance (the squares on the right-hand side). Black and grey symbols represent sessions without and with communication, respectively. The sessions are ranked by the proportion of participants willing to join.

Panel (a) shows demand among high RA participants. They are willing to join insurance in both treatments. Averaged over sessions, 95.6 percent of participants vote for insurance in the group insurance treatment, and 91.6 percent of participants are willing to join individual insurance. A one-sided Mann-Whitney test confirms that these statistics do not significantly differ.

Panel (b) focuses on low RA participants. Demand is again high under group insurance. On average, 81.7 percent of low RA participants vote for insurance in the first round. Under individual insurance, the low RA type is significantly less willing to join, and only 47.4 percent takes insurance. These are large differences, and indeed, individual insurance sessions rank significantly lower than group insurance sessions $(p<0.01)$.

To test whether these findings are robust to the inclusion of control variables, Table 3 estimates a linear probability model for demand $d_{i s}$. This variable indicates whether client $i$ in session $s$ is willing to join insurance in the first round. The estimating equation in Columns (1)-(2) and (5)-(6) is:

$$
d_{i s}=\alpha+\beta_{I I} I I_{s}+\beta_{x} x_{i s}+\varepsilon_{i s}
$$

where $I I_{s}$ is a dummy variable for individual insurance, using group insurance as a base level; $x_{i s}$ a vector of controls that are significantly correlated with demand (see Appendix Table A4 and $\varepsilon_{i s}$ is an individual-specific residual, assumed to be uncorrelated with the regressors.

The table presents the estimated coefficient $\hat{\beta}_{I I}$, its clustered standard error, and the one-sided $t$-percentile in a clustered wild bootstrap for $\beta_{I I}<0.20$ Odd and

\footnotetext{
${ }^{19}$ Included controls are the number of low RA peers, the number of years the participant has been a member of the MFI, whether the participant has an outstanding loan, whether the participants plays with someone from her real microcredit group, and the proportion of rounds that a participant was ill in the risk aversion game.

${ }^{20}$ Clustering is at the session level, and the bootstrap uses Rademacher weights.
} 
even columns present estimated coefficients from the models without and with controls, respectively. Clustering at the session level limits our degrees of freedom. We therefore feel most comfortable interpreting the findings without controls, and include the even columns mainly to assess whether potential imbalances in characteristics across treatments affect the main findings. Appendix Table A1 presents the full model for the even columns with control variables.

Columns (1)-(2) estimate Equation (6) for high RA participants. Individual insurance reduces demand by 3.3 percentage points compared to group insurance in Column (1). This difference is small and statistically insignificant. Results with controls in Column (2) are comparable. The results are also similar in size and significance to the non-parametric session-level estimates.

Columns (5)-(6) estimate the same model for low RA participants. A large share (85.2 percent) is willing to join group insurance. Individual insurance reduces demand significantly by 39.2 percentage points in Column (5). This estimate is robust to the inclusion of controls in Column (6). Although the coefficient decreases in size, it remains large and statistically significant $(p<0.05)$. Thus, the slight imbalance in observed variables between treatments cannot account for the large difference in demand among low RA clients.

In sum, in the first round of the joint liability game, we find large differences in demand between group and individual insurance only for low RA clients, consistent with the theoretical predictions. The difference in demand between the two treatments is also significantly more negative for the low RA type, as indicated by the one-sided $t$-percentiles in the row labeled 'P(Low RA < High RA)' $(p<0.01)$.

\subsection{The number of low RA peers}

Section 2 predicted insurance demand for clients who believe that all peers will enroll, in order to identify free-riding. For clients who believe that some peers will not enroll, suboptimal demand for individual insurance can also be due to coordination failures. Therefore, we isolate the effect of individual insurance for

clients with only high RA peers, who are believed to enroll, and estimate the 
following equation:

$$
d_{i s}=\alpha+\beta_{I I} I I_{s}+\beta_{L} L_{i s}+\beta_{I I * L} I I_{s} \times L_{i s}+\beta_{x} x_{i s}+\varepsilon_{i s},
$$

where $I I_{s} \times L_{i s}$ is the interaction of individual insurance with the number of low RA peers, $L_{i s}$. This interaction term is zero for participants without low RA peers, so that $\beta_{I I}$ now captures the difference in demand for group versus individual insurance among participants with only high RA peers. A negative estimate can be interpreted as free-riding: the client is willing to join group insurance, but not individual insurance, even though she believes that all her peers will enroll.

Columns (3) and (4) in Table 3 estimate Equation (7) for high RA participants. Demand for individual insurance in groups with only high RA peers is on average 2.4 percentage points lower than for group insurance in Column (3). This is not statistically significant, consistent with Hypothesis 1. Estimates with controls in Column (4) are again qualitatively similar.

We find a very small interaction effect between individual insurance and the number of low RA peers in the first round. For high RA participants with one low RA peer, individual insurance reduces demand by $2.5+0.5=2.9$ percentage points, and every additional low RA peer increases the difference between group insurance and individual insurance by 0.5 percentage points. ${ }^{21}$ These estimates suggest that the vast majority of high RA participants with free-riding low RA peers do not retaliate by staying uninsured themselves, warranting the assumption underlying Hypothesis 2 that low RA clients believe all high RA peers will enroll.

The estimates of Equation (7) in Column (7) show that the demand for individual insurance of low RA participants without low RA peers is 19.3 percentage points lower than for group insurance $(p<0.10)$. These findings, combined with the high enrollment rates among their high RA peers, suggest that one-fifth of low RA clients with only high RA peers is free-riding in this first round, providing

\footnotetext{
${ }^{21}$ We find similar results when we replace the number of low RA peers in Equation (7) with a binary indicator for whether a client has at least one low RA peer. For participants with low RA peers, individual insurance reduces demand with a small and insignificant 2.2 percentage points.
} 
evidence of Hypothesis 2. Nevertheless, a non-negligible proportion of low RA clients decides to enroll in individual insurance.

The large effects in Column (5) are partly driven by suboptimal demand among clients with low RA peers. Every additional low RA peer reduces the difference in demand between group and individual insurance by 17.0 percentage points, which can be attributed either to free-riding or to coordination failures. Regardless, the social dilemma appears larger in groups with a larger share of low RA participants.

Column (8) includes the standard set of control variables. The estimates for low RA participants are less precise and the differences are no longer statistically significant. Nevertheless, given the low sample size, it is reassuring that the point estimates in Columns (7) and (8) are similar in magnitude.

\subsection{Social interaction}

Social ties and communication may enhance cooperation in microcredit groups (Cassar et al., 2007). It can create focal points, reinforce social norms and further reveal types, in particular in the first round of the game when participants have not yet observed their peers' decisions in the joint liability game. Table 4 therefore exploits exogenous variation in whether participants could communicate and were assigned to peers from their real credit group, to investigate whether suboptimal demand for individual insurance persists in the presence of social interaction.

Columns (1)-(2) and (5)-(6) present the total effect of individual insurance in the first round for all treatments, and for treatments without and with communication separately, based on the following equation:

$$
d_{i s}=\alpha+\beta_{I I} I I_{s}+\beta_{C} C_{s}+\beta_{I I * C} I I_{s} * C_{s}+\beta_{x} x_{i s}+\varepsilon_{i s}
$$

where $C_{s}$ indicates sessions in the communication treatment, and $I I_{s} \times C_{s}$ its interaction with individual insurance. Sample sizes are too low to estimate Equation (7) with interaction effects for communication.

The first row presents the coefficient on individual insurance, $\beta_{I I}$, when esti- 
mating this equation without interaction term, $\beta_{I I * C}=0$. Estimates in Columns (1)-(2) and (5)-(6) are very similar in size and significance to the respective coefficients in Table 3, which does not include communication as a control variable.

The second and third row, based on the estimate of Equation (8), presents the effect of individual insurance without and with communication, respectively, i.e. $\hat{\beta}_{I I}$ and $\hat{\beta}_{I I}+\hat{\beta}_{I I * C}{ }^{22}$ Columns (1)-(2) and (5)-(6) focus on high RA and low RA participants, respectively. Individual insurance affects demand only for low RA participants, independent of whether participants are able to communicate.

Why does suboptimal demand among low RA participants persist when groups were allowed to verbally interact? The transcripts of the recorded communication demonstrate that participants were very much aware of free-riding:

"We all agreed from the start that we take health insurance but one person betrayed us. It is nothing but greed. He fell sick and now we have to contribute for him."

Nonetheless, communication was not sufficient to enforce the social optimum. Although participants condemned their peers for not taking insurance, and these peers promised to take insurance, communication sometimes remained cheap talk as acknowledged by a frustrated participant:

"Although we discuss and reach an agreement here, some of us are going to change their mind when they proceed to the assistant." [from whom the participant could purchase insurance]

In fact, communication might have given low RA participants a signal that they could free-ride at zero cost. Appendix C.3 predicts that low RA participants' incentive to free-ride increases in the number of peers that will enroll. This is because a higher number of insured peers reduces the group default risk. Although we do not have the statistical power to formally test this mechanism, the model

\footnotetext{
${ }^{22}$ The $t$-percentiles for the test $\beta_{I I}+\beta_{I I * C}<0$ are based on the transformed model $d_{i s}=\alpha+\theta_{1} I I_{s}+\theta_{2} C_{s}+\theta_{3}\left(I I_{s} *\right.$ $\left.C_{s}-1\right)+\theta_{4} x_{i s}+\varepsilon_{i s}$, where $\theta_{1}=\beta_{I I}+\beta_{I I * C}$. The simulated data in the wild bootstrap procedure are generated under the null hypothesis that $\theta_{1}=0$, and the bootstrap procedure yields the $t$-percentile for the alternative hypothesis that $\theta_{1}<0$.
} 
can explain why free-riding is so pronounced in the communication treatment.

Columns (3)-(4) and (7)-(8) test whether individual insurance also reduces demand in the presence of close social ties. The patterns are similar to our findings for communication; individual insurance reduces demand among low RA participants, even when their peers in the game are from the same real microcredit group. Our experimental evidence of free-riding is not an artifact of anonymous groups, and may well generalise to real credit groups with frequent social interactions.

\subsection{Time dynamics}

The previous sections focused on demand in the first round of the game in order to test our hypotheses in the absence of time dynamics. This section investigates decisions in later rounds, when wealth effects, selective attrition, updating of beliefs, and strategic interactions may influence participants' willingness to join insurance, as discussed in Section 2.5 .

Figure 3 shows the willingness to join insurance in each round by participant type. Panel (a) shows that the demand for individual insurance of high RA participants drops slightly below group insurance after the first round but this is statistically insignificant. By contrast, demand among low RA participants in Panel (b) is significantly lower for individual than for group insurance throughout the game ( $p<0.05$ for round 5 and $p<0.01$ otherwise in a one-sided rank sum test).

These descriptives are subject to attrition bias. Panels (a) and (b) in Figure 4 plot the cumulative percentage of participants out of the game after default for high RA and low RA participants, respectively. The figure shows substantial default rates, especially in the group insurance treatment. Under group insurance, one member voting against insurance bars her peers from enrolling as well, so that the group has a high default probability. This may increase observed demand for group insurance in later rounds. Under individual insurance, uninsured clients are scattered over groups, reducing the default risk substantially.

Table 5 estimates Equations (6) and (7) for rounds 2 to 4, without and with con-

trols in the odd and even columns, respectively. In these rounds, participants only 
knew that they would play the game for a large number of rounds, so that these rounds are most comparable. $\sqrt{23}$ To reduce the bias due to selective attrition, the estimates treat every participant instead of every decision as the unit of observation. The outcome variable of interest is therefore the proportion of rounds willing to join insurance while still in the game. The table also shows the estimates' lower and upper bounds by assuming that participants who defaulted earlier in the game are either all unwilling or willing to join. ${ }^{24}$

For the full sample of high RA participants, individual insurance reduces demand by 4.7 percentage points in Column (1), which is not statistically significant. This finding is robust to the inclusion of participants who dropped out of the game, as shown in the lower- and upper-bound interval. Individual insurance would have increased demand by 0.2 percentage points or decreased demand by 5.1 percentage points if drop-outs were all unwilling or willing to join, respectively. The estimated differences are only slightly larger than the first round estimates in Table 3, suggesting limited effects of dynamic mechanisms. Including controls in Column (2) does not affect the results. 25

Columns (3) and (4) estimate Equation (7), distinguishing between high RA participants without and with low RA peers, and find similar results. Further, every additional low RA peer in the individual insurance treatment reduces demand by a small 0.2 percentage points, which means that we find no evidence of the dynamic sanctions derived in Appendix C.2. High RA participants enroll in individual insurance, irrespective of whether they have free-riding low RA peers.

The difference in demand is substantially more pronounced for the low RA type. The average proportion of rounds that they are willing to join is 43.4 per-

\footnotetext{
${ }^{23}$ Appendix Table A3 also includes rounds 5 and 6 when the exogenous termination shock through the roll of a die was introduced, which may have affected participants' perceived continuation values and reduced their willingness to join. This does not affect the results.

${ }^{24}$ We have also performed all analyses using the decision per round as unit of observation. To control for selective attrition in these analyses, we have a) estimated a Heckman selection model, and b) imputed missing observations with either the last-round decision or a predicted insurance decision. The key results are very similar to the results presented here and are available upon request.

${ }^{25}$ In analogy to Table 4 for demand in the first round, Appendix Table A2 estimates the effect of individual insurance without and with communication, and without and with social ties, for later rounds (including rounds 2 to 4 ). We find a similar pattern as in Table 3 with one exception: Individual insurance slightly reduces demand among high RA participants with social ties $(p<0.05)$. Potentially, wealth effects have induced this subsample to free-ride.
} 
centage points lower for individual compared to group insurance in Column (5), and individual insurance reduces demand among low RA types with only high RA peers by 27.7 percentage points in Column (7). Consistent with the free-riding hypothesis, a substantial proportion of low RA clients opts out, even when all peers consistently enroll throughout the game. Finally, every additional low RA peer reduces the difference in demand between group and individual insurance with 15.1 percentage point, magnifying the social dilemma.

To conclude, we find substantial evidence of the free-riding hypothesis. Demand is high in the group insurance treatment, which means that full group enrollment is welfare-enhancing even for low RA participants. However, a large share of low RA participants forgoes individual insurance at the expense of their insured peers. Despite the repeated nature of the game, the threat of retaliation is not sufficiently strong to prevent all low RA participants from free-riding. Throughout the game, relatively few high RA participants condition enrollment on the behavior of peers. Communication and social ties do not enhance cooperation either.

These patterns stand in contrast to findings from conventional laboratory experiments in at least two respects. First, the tolerance towards free-riders in this framed field experiment diverges from the high punishments observed even in the last round of conventional public good games. Second, given this tolerance towards free-riding, it is perhaps surprising that a non-negligible number of low RA participants decides to cooperate. Despite their reluctance to take insurance in the risk aversion game without joint liability, these participants enroll when grouped with other clients, independent of whether they can communicate or play with members from their real credit group. A question for future research is whether this may be due to social norms of solidarity among microfinance clients.

\section{Conclusion}

In the absence of formal insurance, microfinance institutions often use groupbased lending to reduce default rates. Although risk-pooling in microcredit groups 
provides insurance for health expenditures, groups still default if too many members fall ill. Demand for affordable micro health insurance nevertheless remains low. This study provided and tested an explanation for low enrollment rates.

We showed that the individual insurance decision in jointly liable credit groups entails a social dilemma. In theory, less risk averse clients forgo individual insurance and free-ride on peers' contributions in case of health shocks, even when the group is better off if they enroll. Group insurance precludes these clients from free-riding and raises demand for insurance to optimal levels.

To empirically test our theoretical framework, microinsurance games played with 355 microcredit clients in Tanzania elicited demand for individual versus group insurance. This experiment yielded substantial evidence of free-riding. Early in the game, 85.2 percent of less risk averse participants was willing to join group insurance, but only 46.0 percent joined individual insurance, and this difference increased over time - even when peers consistently enrolled throughout the game. In contrast, more risk averse clients coordinated on the social optimum.

This study sheds light on the replicability of findings from conventional public goods games played in the laboratory. Consistent with such games, the social dilemma in our framed field experiment resulted in suboptimal outcomes. An open question is why the high RA participants did not sanction their free-riding peers, as is common in the lab, and why a number of low RA members cooperated even though free-riding was not sanctioned. The microcredit frame combined with the non-standard type of participant may have evoked a different set of norms than commonly observed among student populations. This illustrates how external validity remains a caveat of conventional laboratory experiments.

The results suggest that the choice to offer insurance either at the individual or at the group level should reach beyond administrative considerations or the standard concern for adverse selection. Because members of jointly liable credit groups share risk, strategic decisions in such groups can be an important determinant of the demand for microinsurance. Group insurance eliminates the opportunity to free-ride on peers, and increases the willingness to join insurance. 
However, a small minority of individuals consistently voted against group insurance. This also prevented their peers from enrolling, undermining the beneficial effects of group insurance on take-up. Adopting a less strict voting rule than unanimity, or allowing exemptions for some clients may attenuate such unintended consequences. Further, group insurance is not the only way to prevent free-riding. Alternatives are for instance mandatory enrollment, stronger social sanctions, individual liability for loan repayment, or an individual insurance product that only steps in if too many group members simultaneously incur a shock.

The microinsurance games resembled the real world of the Tujijenge microcredit groups as closely as possible. Nevertheless, the demand for microinsurance in jointly liable credit groups depends on more factors than can be studied simultaneously in a game. A promising area for further research is to analysedynamics between insurance and endogenous group formation. The introduction of insurance may affect the optimal group composition. Insurance may for instance induce sorting on preferences for formal insurance versus social risk-sharing. While microinsurance schemes are currently rolled out to existing microcredit group members who face high switching costs, insurance may well affect the composition of new microfinance groups, which in turn will influence demand for insurance.

To conclude, we find suboptimal demand for individual insurance because jointly liable microcredit group members free-ride on their peers. This is not only relevant for the design of ongoing pilots of health insurance schemes, but also for other types of microinsurance. Moreover, since social risk-sharing arrangements exist beyond the credit group, the findings may generalise to other pre-existing risk pools such as neighbors, migrant networks, informal savings groups or cooperatives. As such, our model may help explain low uptake in a wide range of microinsurance schemes. 


\section{References}

Abbink, K., Irlenbusch, B., Renner, E., and Street, H. (2006). Group size and social ties in microfinance institutions. Economic Inquiry, 44(4):614.

Aghion, D., Armendariz, B., and Gollier, C. (2000). Peer group formation in an adverse selection model. Economic Journal, 110(465):632-643.

Armendariz, B. and Morduch, J. (2010). The Economics of Microfinance. The MIT Press: Cambridge, MA.

Attanasio, O., Barr, A., Cardenas, J., Genicot, G., and Meghir, C. (2012). Risk pooling, risk preferences, and social networks. American Economic Journal: Applied Economics, 4(2):134-167.

Battigalli, P. and Dufwenberg, M. (2007). Guilt in games. American Economic Review, 97(2):170-176.

Beck, T. and Cull, R. (2013). Banking in Africa. World Bank Policy Research Working Paper, 6684.

Besley, T. and Coate, S. (1995). Group lending, repayment incentives and social collateral. Journal of Development Economics, 46(1):1-18.

Bó, P. (2005). Cooperation under the shadow of the future: Experimental evidence from infinitely repeated games. American Economic Review, 95(5):1591-1604.

Browne, M. (1992). Evidence of adverse selection in the individual health insurance market. Journal of Risk and Insurance, 59(1):13-33.

Bruhn, M. and McKenzie, D. (2009). In pursuit of balance: Randomization in practice in development field experiments. American Economic Journal: Applied Economics, 1(4):200-232. 
Cameron, A., Gelbach, J., and Miller, D. (2008). Bootstrap-based improvements for inference with clustered errors. Review of Economics and Statistics, 90(3):414-427.

Cardenas, J. and Carpenter, J. (2008). Behavioural development economics: Lessons from field labs in the developing world. Journal of Development Studies, 44(3):311-338.

Cassar, A., Crowley, L., and Wydick, B. (2007). The effect of social capital on group loan repayment: Evidence from field experiments. Economic Journal, 117(517):F85-F106.

Charness, G. and Dufwenberg, M. (2011). Participation. American Economic Review, 101(4):1211-1237.

Cole, S., Giné, X., Tobacman, J., Topalova, P., Townsend, R., and Vickery, J. (2013). Barriers to household risk management: Evidence from India. American Economic Journal: Applied Economics, 5(1):104-135.

Cox, J. C., Sadiraj, V., and Schmidt, U. (2011). Paradoxes and mechanisms for choice under risk. Kiel Working Papers, 1712.

De Allegri, M., Sauerborn, R., Kouyaté, B., and Flessa, S. (2009). Community health insurance in sub-Saharan Africa: What operational difficulties hamper its successful development? Tropical Medicine $\mathcal{E}$ International Health, 14(5):586-596.

De Janvry, A., Dequiedt, V., and Sadoulet, E. (2014). The demand for insurance against common shocks. Journal of Development Economics, 106:227-238.

Dercon, S., Gunning, J., and Zeitlin, A. (2011). The demand for insurance under limited credibility: Evidence from Kenya. Paper presented at Midwest Economic Development Conference, University of Wisconsin-Madison. 
Fehr, E. and Gächter, S. (2000). Cooperation and punishment in public goods experiments. American Economic Review, 90(4):980-994.

Fischer, G. (2013). Contract structure, risk-sharing, and investment choice. Econometrica, 81(3):883-939.

Genicot, G. and Ray, D. (2003). Group formation in risk-sharing arrangements. Review of Economic Studies, 70(1):87-113.

Gertler, P. and Gruber, J. (2002). Insuring consumption against illness. American Economic Review, 92(1):51-70.

Ghatak, M. and Guinnane, T. W. (1999). The economics of lending with joint liability: Theory and practice. Journal of Development Economics, 60(1):195228.

Giné, X., Jakiela, P., Karlan, D., and Morduch, J. (2010). Microfinance games. American Economic Journal: Applied Economics, 2(3):60-95.

Giné, X. and Karlan, D. (Forthcoming). Group versus individual liability: Short and long term evidence from Philippine microcredit lending groups. Journal of Development Economics, page to appear.

Harrison, G. and Swarthout, J. T. (2012). The Independence Axiom and the bipolar behaviorist. Georgia State University CEEL working paper, 1.

Harrison, G. W. and List, J. A. (2004). Field experiments. Journal of Economic Literature, 42(4):1009-1055.

Holt, C. and Laury, S. (2002). Risk aversion and incentive effects. American Economic Review, 92(5):1644-1655.

McGuire, T. (2012). Demand for health insurance. In Pauly, M., McGuire, T., and Barros, P., editors, Handbook of Health Economics, chapter 5, pages 317-396. Elsevier, Oxford, UK. 
Mobarak, A. and Rosenzweig, M. (2012). Selling formal insurance to the informally insured. Yale University Economic Growth Center Discussion Paper, 1007.

Quiggin, J. (1982). A theory of anticipated utility. Journal of Economic Behavior $\mathcal{E}$ Organization, 3(4):323-343.

Sally, D. (1995). Conversation and cooperation in social dilemmas. Rationality and Society, 7(1):58.

Tversky, A. and Kahneman, D. (1992). Advances in prospect theory: Cumulative representation of uncertainty. Journal of Risk and uncertainty, 5(4):297-323.

Vanberg, C. (2008). Why do people keep their promises? An experimental test of two explanations. Econometrica, 76(6):1467-1480. 


\section{Figures and Tables}

Figure 1: Game tree.

The symbol $d_{i t}$ indicates insurance status, $p$ the health shock probability, $H_{i t}$ health status, $\pi_{i t}$ income before contributing, $e$ revenue net of the loan $l, h$ health expenditures, $F_{t}$ the number of delinquents, $c_{i t}$ the contribution, and $V_{i, t+1}$ the continuation value from future loan cycles.

(a) Theoretical framework

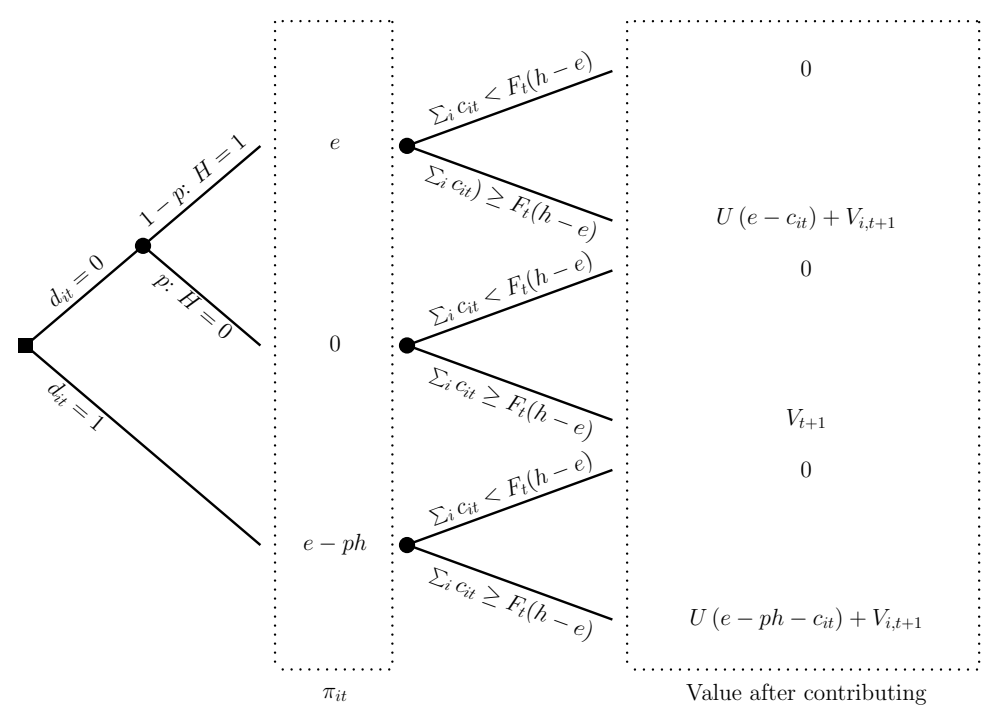

(b) Experimental application

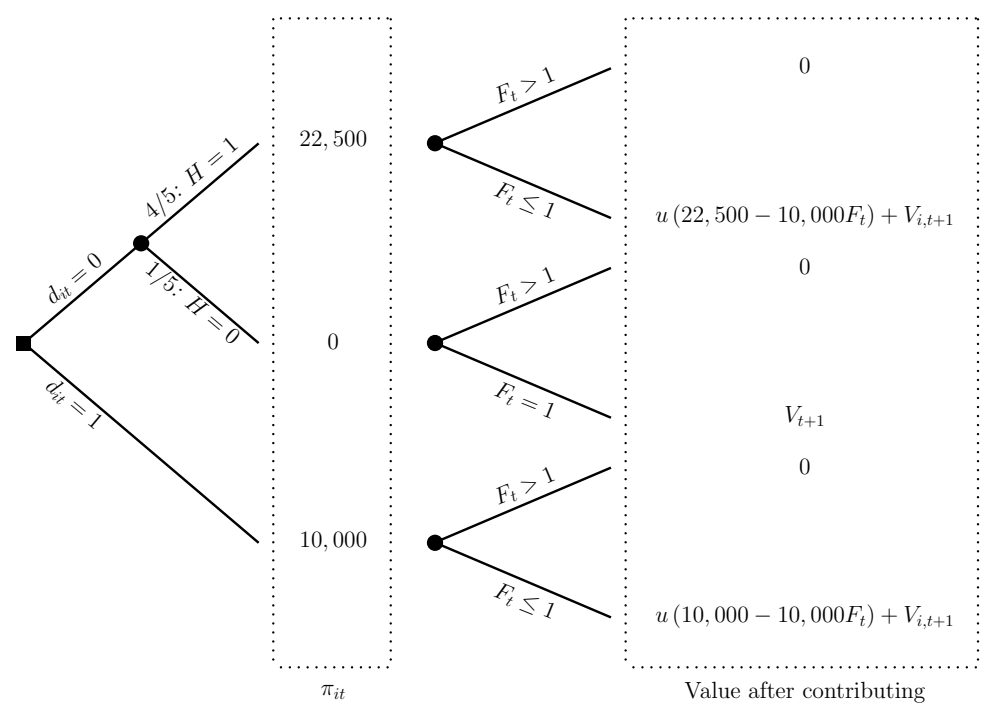


Figure 2: Group Insurance versus Individual Insurance by Session

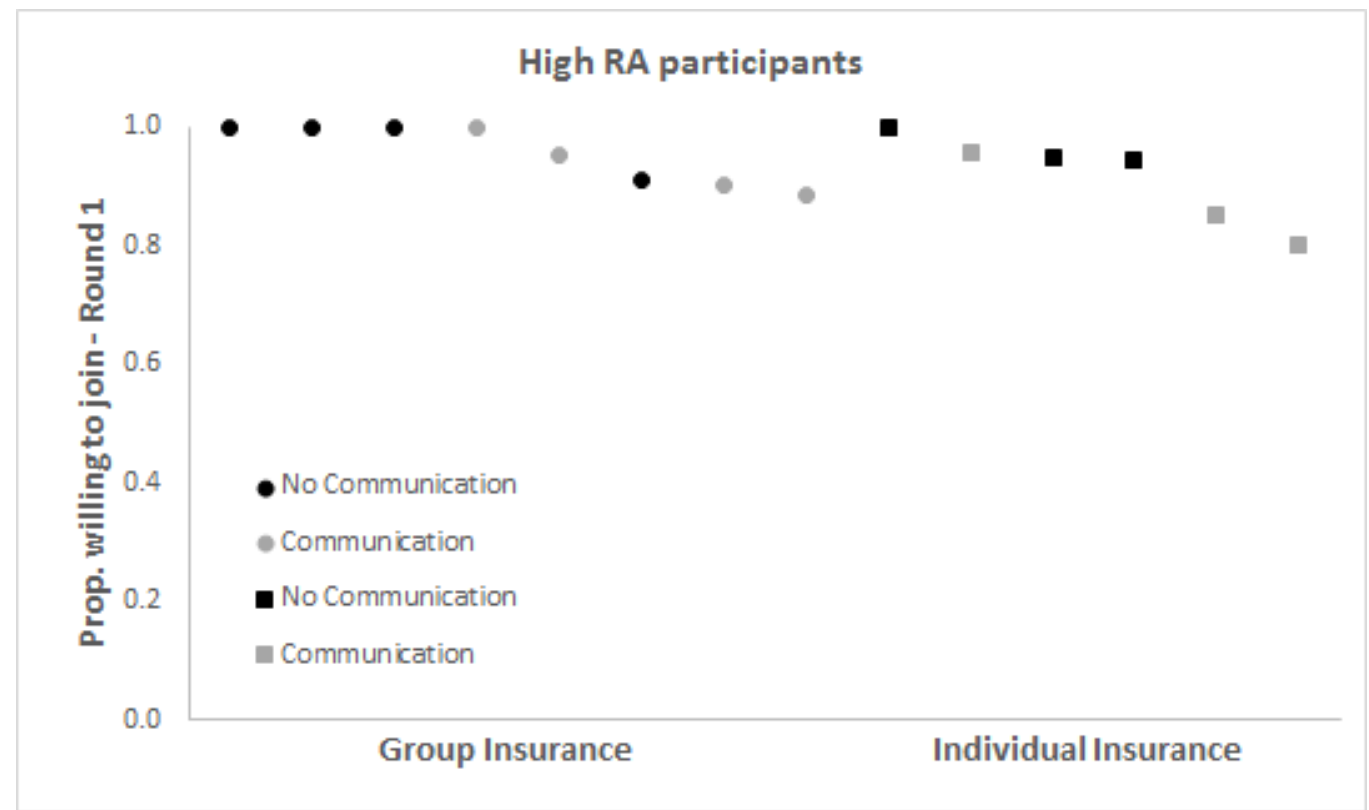

(a) Proportion of participants with high risk aversion willing to join - Round 1.

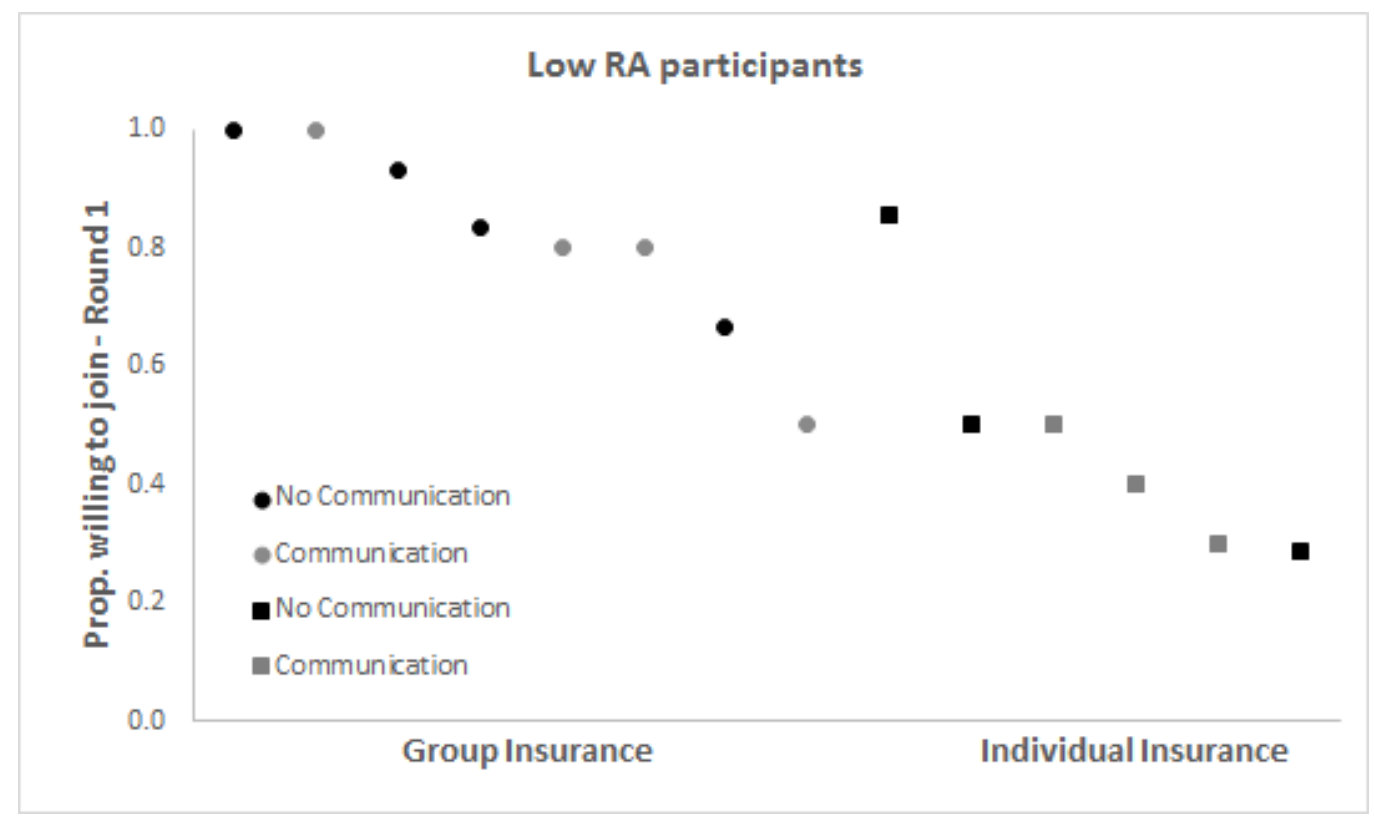

(b) Proportion of participants with low risk aversion willing to join - Round 1. 
Figure 3: Group Insurance versus Individual Insurance by round

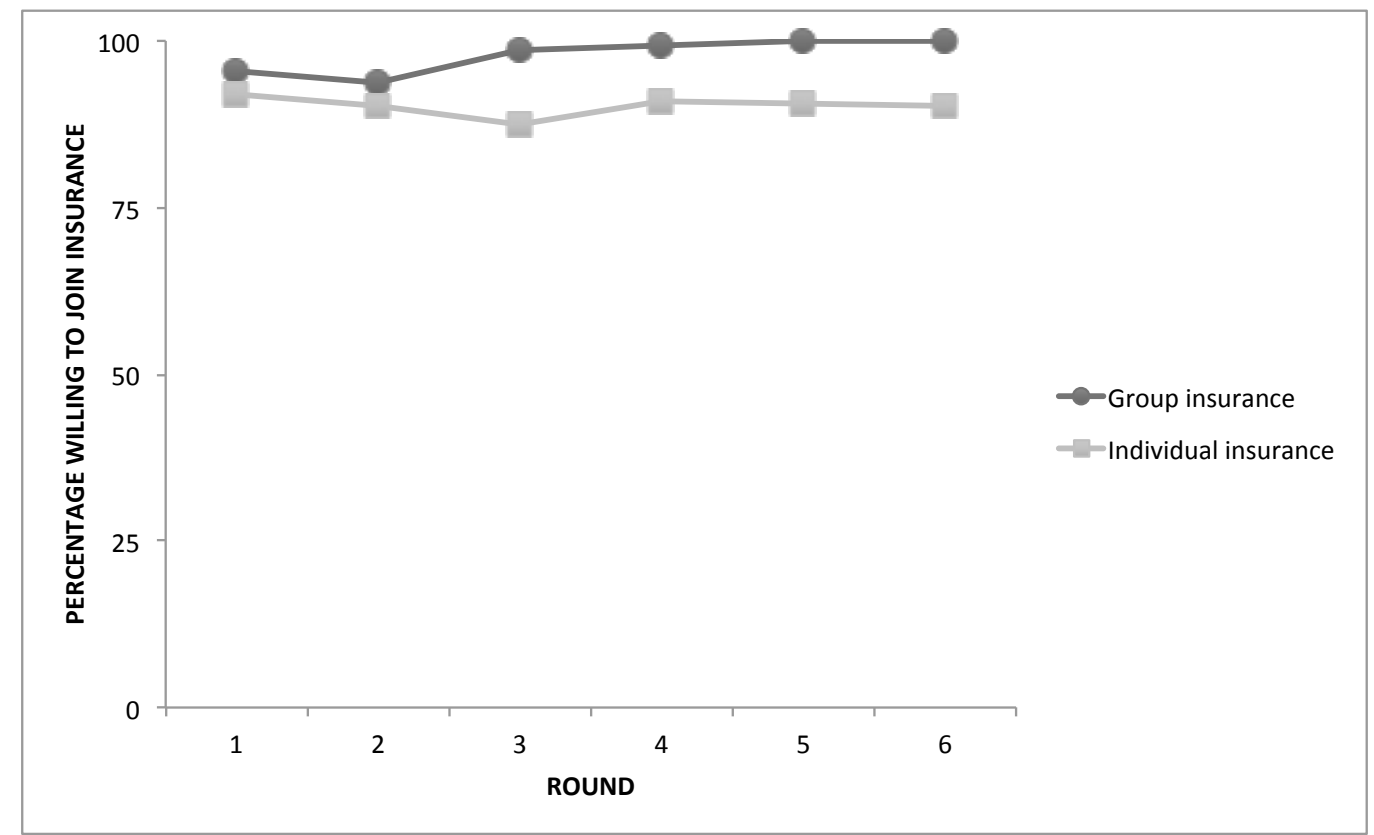

(a) Percentage of participants with high risk aversion willing to join

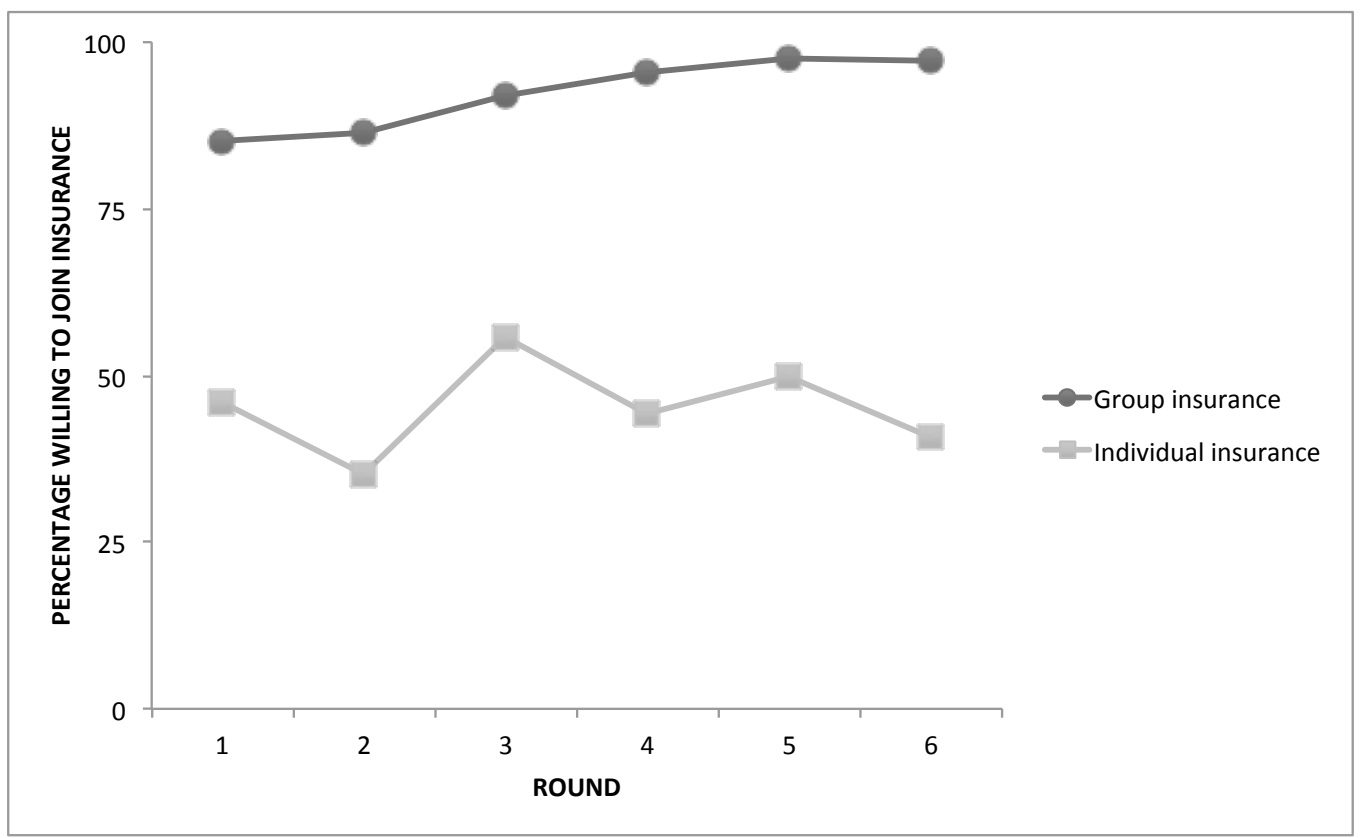

(b) Percentage of participants with low risk aversion willing to join 
Figure 4: Cumulative default rates by type of insurance and round

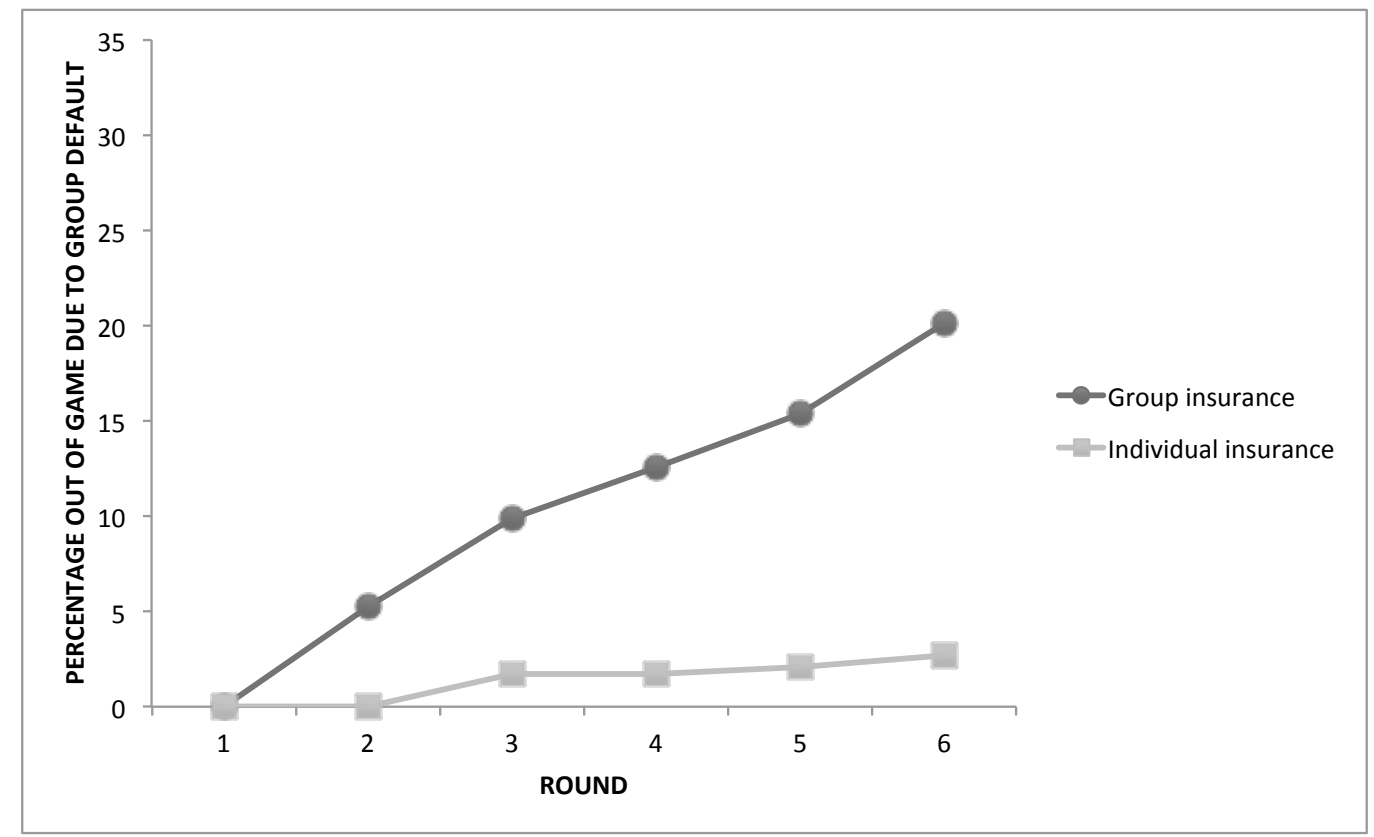

(a) Percentage of participants with high risk aversion out of game due to default

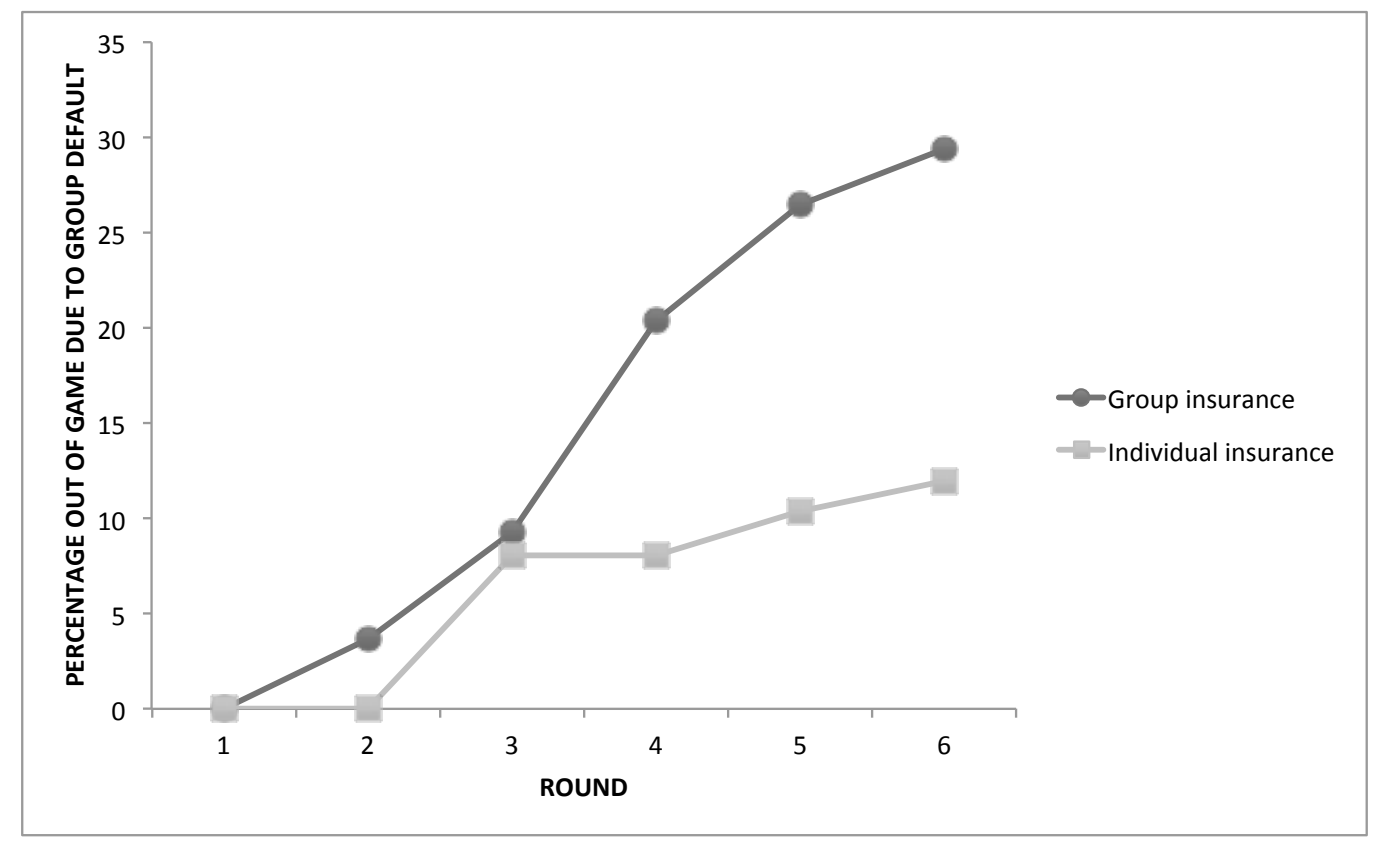

(b) Percentage of participants with low risk aversion out of game due to default 
Table 1: Descriptives of participants and the study population

\begin{tabular}{|c|c|c|c|c|c|c|c|c|}
\hline & \multicolumn{2}{|c|}{ Games } & \multicolumn{2}{|c|}{ Tujijenge } & \multicolumn{4}{|c|}{ Probit for Low Risk Aversion } \\
\hline & (1) & (2) & (3) & (4) & (5) & (6) & (7) & $(8)$ \\
\hline & Mean & (s.d.) & Mean & (s.d.) & Coeff. & (s.e.) & Coeff. & (s.e.) \\
\hline \multicolumn{9}{|c|}{ A. Demographic and socio-economic characteristics } \\
\hline Female & 74.6 & & $67.8^{* *}$ & & -0.078 & $(0.067)$ & $-0.109^{*}$ & $(0.062)$ \\
\hline Married & 76.1 & & 80.8 & & 0.004 & $(0.064)$ & -0.009 & $(0.060)$ \\
\hline Age & 36.0 & (8.5) & 36.0 & (9.2) & -0.176 & $(0.119)$ & -0.165 & $(0.113)$ \\
\hline Household size & 5.1 & (2.1) & $4.6^{* * *}$ & (1.8) & $0.029^{*}$ & $(0.016)$ & $0.027^{*}$ & $(0.014)$ \\
\hline Years of education & 7.7 & (2.4) & $8.2^{* *}$ & (2.7) & 0.014 & $(0.012)$ & 0.013 & $(0.011)$ \\
\hline Per capita HH income & 84.4 & $(60.4)$ & 82.7 & $(76.9)$ & 0.033 & $(0.050)$ & 0.035 & $(0.032)$ \\
\hline \multicolumn{9}{|l|}{ B. Health characteristics } \\
\hline Visited provider & 54.9 & & $24.8^{* * *}$ & & -0.025 & $(0.061)$ & -0.015 & $(0.058)$ \\
\hline Other visited provider & 73.5 & & $37.6^{* * *}$ & & 0.008 & $(0.086)$ & 0.010 & $(0.080)$ \\
\hline HH health expenses & 43.0 & $(80.9)$ & 32.5 & $(302)$ & -0.015 & $(0.010)$ & $-0.017^{*}$ & $(0.009)$ \\
\hline Nr. times foregone care & 0.6 & $(1.4)$ & & & 0.015 & $(0.019)$ & & \\
\hline Knows insurance & 41.1 & & & & 0.013 & $(0.057)$ & & \\
\hline Has insurance & 7.3 & & $11.2^{*}$ & & $0.238^{* *}$ & $(0.131)$ & $0.217^{* *}$ & $(0.119)$ \\
\hline \multicolumn{9}{|l|}{ C. Microcredit variables } \\
\hline Business profit & 226 & (205) & & & -0.005 & $(0.041)$ & & \\
\hline Membership years & 1.1 & (1.6) & & & $-0.045^{* *}$ & $(0.021)$ & & \\
\hline Has outstanding loan & 89.0 & & $97.1^{* * *}$ & & -0.150 & $(0.105)$ & $-0.195^{* *}$ & $(0.096)$ \\
\hline Last loan value & 460 & (369) & 425 & $(353)$ & -0.007 & $(0.045)$ & -0.021 & $(0.040)$ \\
\hline Delinquent in group & 32.4 & & & & 0.065 & $(0.084)$ & & \\
\hline Contributed for peer & 27.3 & & & & -0.051 & $(0.081)$ & & \\
\hline Has been delinquent & 13.0 & & & & -0.049 & $(0.105)$ & & \\
\hline Peers contributed & 6.8 & & & & 0.224 & $(0.185)$ & & \\
\hline Nr. real credit group & 0.5 & $(0.8)$ & & & & & & \\
\hline \multicolumn{9}{|l|}{ D. Risk aversion } \\
\hline Low Risk Aversion & 25.6 & & $30.7^{1}$ & {$[23.3,3$} & 3.2] & & & \\
\hline Nr. Low RA peers & 1.025 & $(0.98)$ & & & & & & \\
\hline Observations & 355 & & 407 & & & & & \\
\hline
\end{tabular}

${ }^{*} p<.1,{ }^{* *} p<.05,{ }^{* * *} p<.01 .{ }^{1}$ Out-of-sample prediction and Delta Confidence Interval using (7)-(8). Binary variables presented in \%. Monetary variables are in 1,000 Tanzanian Shillings (TZS), or approx. 0.67 USD. Column (3)-(4): survey among representative sample of Tujijenge clients. The table presents all variables available in both datasets and stars in Column (3) indicate $p$-value of $t$-test for equal means in the two datasets. The probit regressions in Columns (5)-(8) use a log transformation for Age, Per capita household income, Household health expenses, Business profit and Last loan value. 
Table 2: Balance of participants' characteristics and game-related variables

\begin{tabular}{|c|c|c|c|c|c|c|}
\hline & \multicolumn{3}{|c|}{ High RA participants } & \multicolumn{3}{|c|}{ Low RA participants } \\
\hline & $\begin{array}{c}\text { (1) } \\
\text { Group }\end{array}$ & $\begin{array}{c}(2) \\
\text { Individual }\end{array}$ & $\begin{array}{c}(3) \\
p \text {-value }\end{array}$ & $\begin{array}{c}\text { (4) } \\
\text { Group }\end{array}$ & $\begin{array}{c}(5) \\
\text { Individual }\end{array}$ & $\begin{array}{c}(6) \\
p \text {-value }\end{array}$ \\
\hline \multicolumn{7}{|c|}{ A. Demographic and socio-economic characteristics } \\
\hline Female & 75.5 & 77.9 & 0.796 & 68.5 & 70.3 & 0.890 \\
\hline Married & 74.2 & 80.5 & 0.222 & 70.4 & 78.4 & 0.364 \\
\hline Age & 35.8 & 36.8 & 0.502 & 36.4 & 33.2 & 0.176 \\
\hline Household size & 4.9 & 5.4 & 0.134 & 5.5 & 4.8 & 0.430 \\
\hline Years of education & 7.5 & 7.6 & 0.486 & 8.0 & 8.6 & 0.432 \\
\hline Per capita HH income & 83.8 & 83.9 & 0.938 & 82.3 & 91.5 & 0.342 \\
\hline \multicolumn{7}{|l|}{ B. Health characteristics } \\
\hline Visited provider & 55.0 & 60.2 & 0.396 & 50.0 & 45.9 & 0.688 \\
\hline Other visited provider & 77.5 & 75.2 & 0.672 & 64.8 & 64.9 & 0.996 \\
\hline HH health expenses & 47.7 & 48.0 & 0.998 & 31.3 & 25.8 & 0.708 \\
\hline Nr. times foregone care & 0.5 & 0.6 & 0.684 & 0.6 & 0.4 & 0.510 \\
\hline Knows health insurance & 34.4 & 46.0 & $0.068^{*}$ & 42.6 & 51.4 & 0.338 \\
\hline Has health insurance & 2.6 & 8.0 & $0.050^{*}$ & 13.0 & 16.2 & 0.676 \\
\hline \multicolumn{7}{|l|}{ C. Microcredit variables } \\
\hline Business profit & 206.8 & 262.5 & 0.102 & 213.8 & 229.1 & 0.702 \\
\hline Membership years & 1.2 & 1.2 & 0.982 & 0.7 & 0.8 & 0.810 \\
\hline Has outstanding loan & 92.1 & 89.4 & 0.696 & 88.9 & 75.7 & 0.232 \\
\hline Last loan value & 419.1 & 521.7 & 0.206 & 452.7 & 448.6 & 1.000 \\
\hline Delinquent in group & 31.8 & 31.0 & 0.890 & 37.0 & 32.4 & 0.740 \\
\hline Contributed for peer & 23.8 & 31.0 & 0.230 & 29.6 & 27.0 & 0.806 \\
\hline Has been delinquent & 13.2 & 11.5 & 0.548 & 20.4 & 5.4 & 0.120 \\
\hline Peers contributed & 7.3 & 4.4 & 0.264 & 14.8 & 0.0 & 0.102 \\
\hline Nr. real credit group & 0.5 & 0.5 & 0.890 & 0.4 & 0.6 & 0.376 \\
\hline \multicolumn{7}{|c|}{ D. Risk aversion and incidence of health shocks } \\
\hline Nr. low RA peers & 0.90 & 1.00 & 0.602 & 1.50 & 0.90 & 0.278 \\
\hline Prop. ill in risk aversion game & 0.2 & 0.1 & 0.154 & 0.3 & 0.2 & 0.106 \\
\hline Prop. ill in joint liability game & 0.2 & 0.2 & $0.088^{*}$ & 0.3 & 0.2 & 0.170 \\
\hline Observations & 151 & 113 & & 54 & 37 & \\
\hline Percentage of treatment & 73.7 & 75.3 & & 26.3 & 24.7 & \\
\hline
\end{tabular}

${ }^{*} p<.1,{ }^{* *} p<.05,{ }^{* * *} p<.01 . p$-values are the two-sided $t$-percentiles based on a wild cluster bootstrap with 999 replications. Binary variables presented in percentages. Monetary variables are in 1,000 Tanzanian Shillings (TZS), or approx. 0.67 USD at exchange rates during the study. 


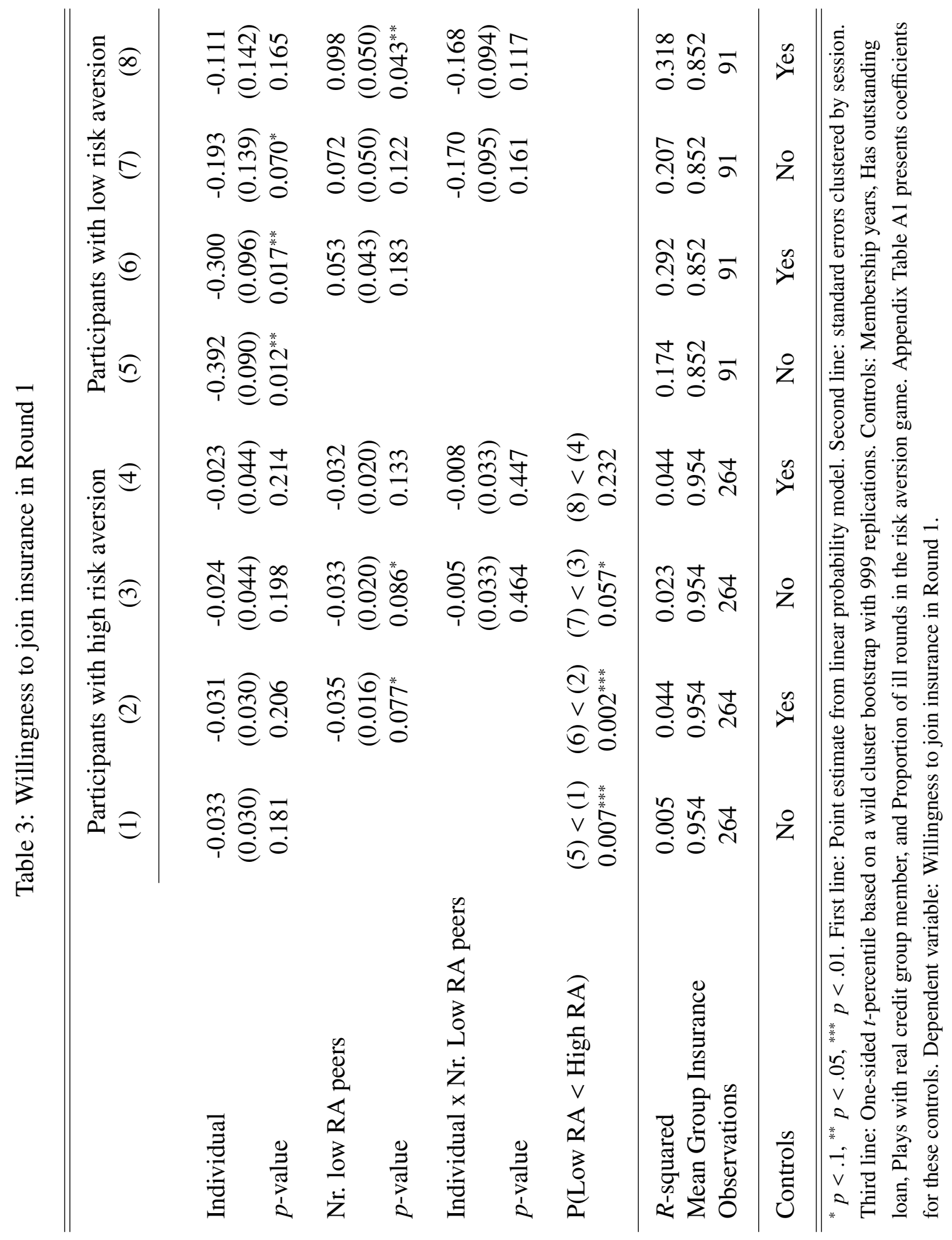




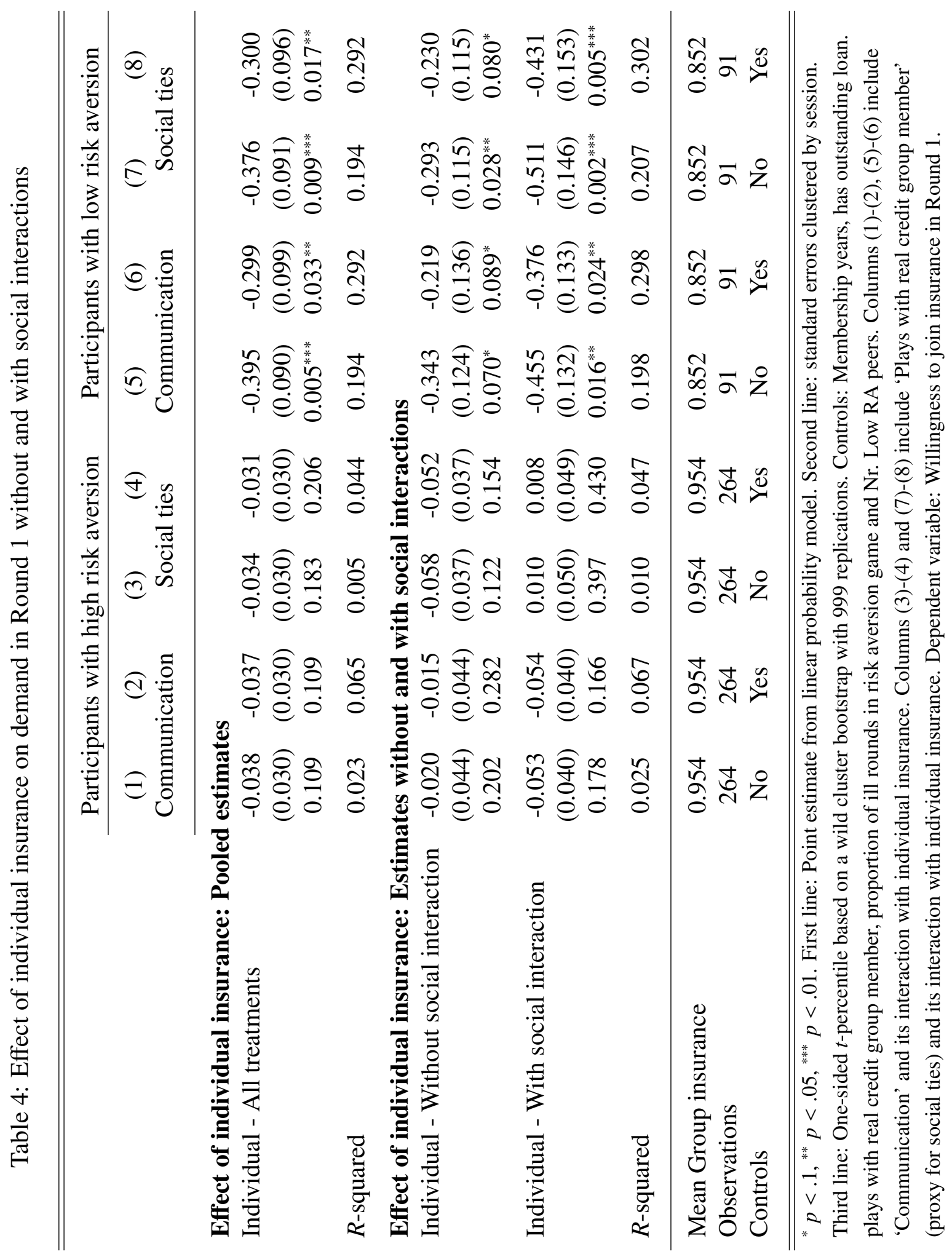




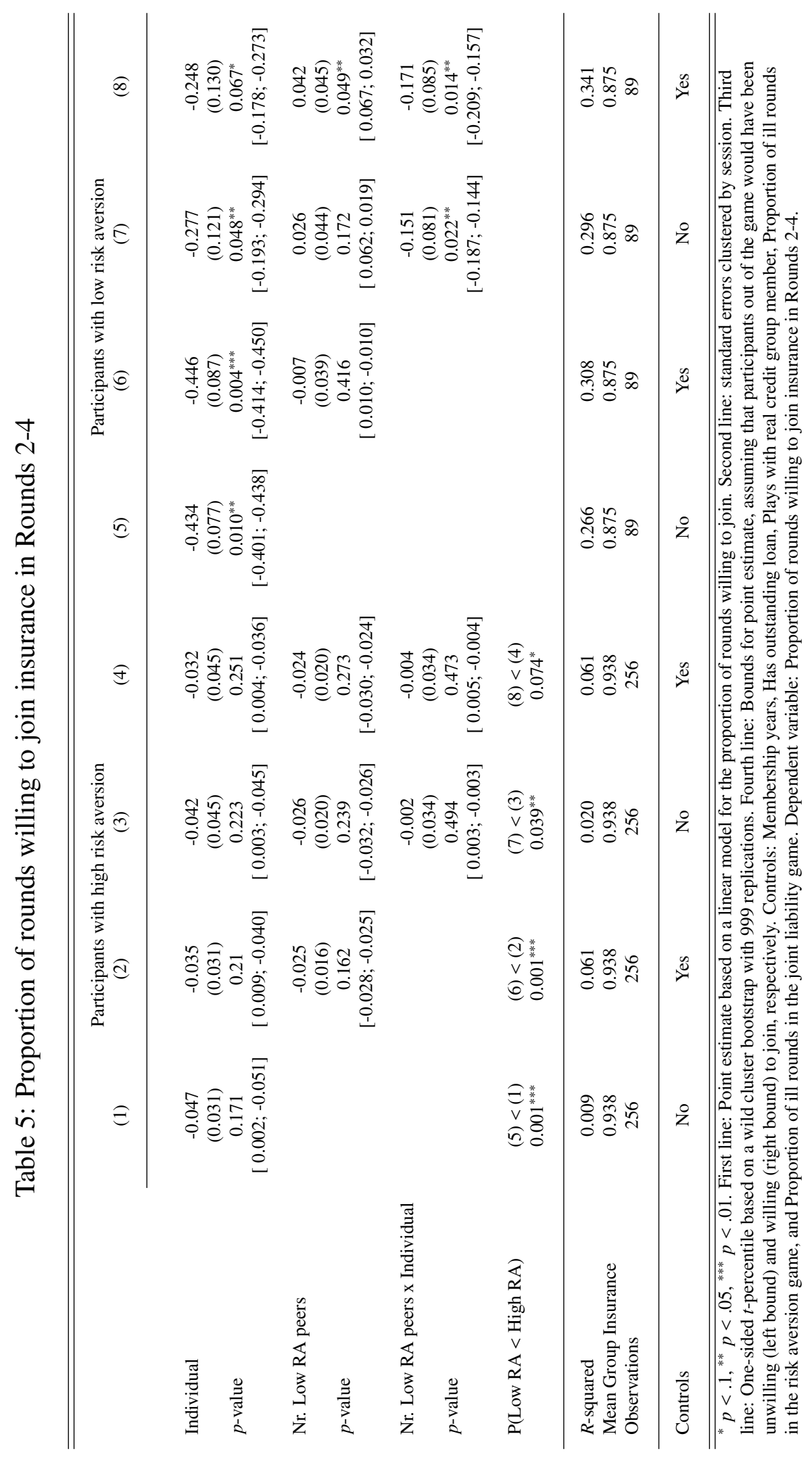




\section{A The continuation value}

This appendix derives the value of continuing to the next loan cycle, i.e. total expected discounted utility from all future loan cycles. This continuation value depends on future insurance decisions and is easiest to specify if future insurance decisions remain constant over time. We therefore illustrate how to derive the continuation value under two scenarios: 'Full Enrollment' (FE), meaning that all clients enroll in every loan cycle, i.e. $d_{i t}=1$ for all $i \in\{1, \ldots, n\}$ and $s \in\{t+1, \ldots, \infty\}$; and 'Zero Enrollment' (ZE), meaning that no client ever enrolls, i.e. $d_{i t}=0$ for all $i \in\{1, \ldots, n\}$ and $s \in\{t+1, \ldots, \infty\}$.

Generally speaking, if we allow for variation in the future number of insured group members $I_{s}$, the value of continuing to loan cycle $t+1$ can be written as:

$$
V_{i, t+1}=\sum_{s=t+1}^{\infty} \beta_{t, s} \Pi_{\tau=t+1}^{s-1} P_{I_{\tau}} \mathrm{E} U\left(Y\left(H_{i s}, d_{i s}, F_{s}^{I_{s}}\right)\right)
$$

The probability of reaching loan cycle $s$ is the product of the continuation probabilities in all past loan cycles, $\prod_{\tau=t+1}^{s-1} P_{I_{\tau}}$, and this term equals one for $s=t+1$. Expected utility from loan cycle $s$ is discounted by this probability and the period- $t$ discount factor $\beta_{t, s}$. Utility depends on consumption $Y_{i s}=Y(\cdot)=\pi_{i t}-c_{i t}$, which in turn depends on client $i$ 's health $H_{i s}$, insurance status $d_{i s}$, and the number of delinquents in the group, $F_{s}^{I_{s}}$.

The continuation value in the $F E$ scenario is defined as client $i$ 's total discounted expected utility if the entire group has insurance in all future loan cycles. In this case, client $i$ 's disposable income is $e-p h$ forever,

$$
V_{i, t+1}(F E) \equiv \sum_{s=t+1}^{\infty} \beta_{t, s} U\left(e-p h ; \theta_{i}\right),
$$

where $\beta_{t, s} \equiv 1 /\left(1-\delta_{t, s}\right)<1$ is the period- $t$ discount factor and $\delta_{t, s}$ the period- $t$ discount rate for loan cycle $s>t$. In the presence of exponential discounting, the discount factor can be expressed as $\beta_{t, s}=\beta^{s-t}$, and the continuation value reduces to a geometric series with an infinite number of terms:

$$
V_{i, t+1}(F E)=\sum_{s=t+1}^{\infty} \beta^{s-t} U\left(e-p h ; \theta_{i}\right)=\frac{\beta}{1-\beta} U\left(e-p h ; \theta_{i}\right)
$$

In the experiment, earnings net of the insurance premium are $e-p h=10$, which can be imputed in the equation above to calculate the value under Full Enrollment.

In the $Z E$ scenario, no client ever enrolls. Client $i$ 's value is then:

$$
V_{i, t+1}(Z E) \equiv \sum_{s=t+1}^{\infty} P_{0}^{s-t-1} \beta_{t, s} \mathrm{E} U\left(H e-c\left(F^{0}, H e\right) ; \theta_{i}\right)
$$


where $F^{0}$ is the random number of delinquent peers if nobody enrolls, binomially distributed with probability $p$ and $N$ trials, and $H e$ represents random income for uninsured clients. Recall that with probability $1-p$, an uninsured client is healthy, $H=1$, and consumes $e-c_{i t}$. With probability $p$, a client is ill, $H=0$, and has zero income. Every loan cycle, the group continues borrowing with probability $P_{0}$, the probability that a fully uninsured group can repay the loan. As a result, conditional on reaching loan cycle $t+1$, a group has access to loans in loan cycle $s \geq t+1$ with probability with probability $P_{0}^{s-t-1}$. Assuming exponential discounting, the continuation value can be written as:

$$
V_{i, t+1}(Z E)=\frac{\beta}{1-\beta P_{0}} \mathrm{E} U\left(H e-c\left(F^{0}, H e\right) ; \theta_{i}\right)
$$

In the experiment, groups can contribute for at most one delinquent. Thus, the probability of continuation in an uninsured group is the probability that at most one group member falls ill, $P_{0}=P\left(F_{t}^{0} \leq 1\right)$. Recall that if no group member has insurance, $I_{t}=0$, the number of delinquents is binomially distributed with $N=5$ and probability $p=1 / 5$. The group hence includes zero delinquents with probability $(1-p)^{N}=(4 / 5)^{5}=0.3277$, and one out of the five potential delinquents with probability $N(1-p)^{N-1} p=(4 / 5)^{4}=0.4096$. As a result, the continuation probability is $P_{0}=(4 / 5)^{4} * 9 / 5=0.7373$.

Consumption within a loan cycle, $\mathrm{He}-c\left(F^{0}, \mathrm{He}\right)$, is distributed as follows. With probility $p=1 / 5$, the client is ill, $H=0$, yielding zero utility. With probability $(1-p)=4 / 5$, the client is healthy and earns $e=22.5$ before contributing for delinquents. Conditional on being healthy, the contribution can take three values. First, with probability $(1-p)^{N-1}=(4 / 5)^{4}$, she has no delinquent peers, contributes nothing, $c(0,22.5)=0$, and consumes 22.5. Second, with probability $(N-1)(1-p)^{N-2} p=(4 / 5)^{4}$, she has one delinquent peer, contributes $c(1,22.5)=10$, and consumes 12.5 . Third, with probability $1-2 *(4 / 5)^{4}$, the client has more than one delinquent, contributes 22.5 , yielding zero consumption.

The continuation value in the 'Zero Enrollment' scenario therefore reduces to:

$$
V_{i, t+1}(Z E)=\frac{\beta}{1-0.737 \beta}\left(\frac{4}{5}\right)^{5}\left[U\left(22.5 ; \theta_{i}\right)+U\left(12.5 ; \theta_{i}\right)\right]
$$

\section{B Proofs}

\section{PROOF PROPOSITION1}

Proof To prove the first part of the proposition, we compare total expected utility if the pivotal client votes for insurance with total expected utility from voting against insurance. If the pivotal 
client votes for insurance, all group members will have insurance and there will be no delinquents in the group. Based on the right-hand side of Panel (a) in Figure 1, the value for client $i$ is:

$$
U\left(e-p h ; \theta_{i}\right)+V_{i, t+1}
$$

The client earns $\pi_{t}=e-p h$ and does not need to contribute for peers. By Assumption (A3), the group fully repays the loan and continues to the next loan cycle with certainty, which has value $V_{i, t+1}$, i.e. total expected utility from future loan cycles conditional on continuing to the next loan cycle.

If the pivotal client votes against insurance, nobody in the group will be insured, and the value for client $i$ will depend on her own health and that of her peers. Using again Figure 1 Panel (a), the value of a vote against insurance is:

$$
\mathrm{E} U\left(H e-c\left(F_{t}^{0}, H e\right) ; \theta_{i}\right)+P_{0} V_{i, t+1}
$$

A healthy client, $H=1$, earns $e$ and contributes $c\left(F_{t}^{0}, e\right)$, which depends on the number of delinquents, $F_{t}^{0}$. If $F_{t}^{0}(h-e)>\left(N-F_{t}^{0}\right) e$, i.e. $F_{t}^{0}>N e / h$, then total earnings among healthy group members - their maximum contribution by Assumption (A1) - are insufficient to repay the full group loan and the contribution by healthy group members is $e$ by Assumption (A2). Else, if $F_{t}^{0} \leq N e / h$, healthy group members jointly contribute $F_{t}^{0}(h-e)$ and repay the full group loan by Assumption (A3). This occurs with probability $P_{0}=P\left(F^{0} \leq N e / h\right)$, and these repaying groups continue to the next loan cycle, which has value $V_{t+1}$.

The client will vote for insurance, $d_{t}^{G I}\left(\theta_{i}\right)=1$, if and only if the expected utility from enrolling as a group is greater than the expected utility from staying uninsured as a group,

$$
U\left(e-p h ; \theta_{i}\right)+V_{i, t+1} \geq \mathrm{E} U\left(H e-c\left(F_{t}^{0}, H e\right) ; \theta_{i}\right)+P_{0} V_{i, t+1},
$$

and otherwise she will vote against insurance, $d_{t}^{G I}\left(\theta_{i}\right)=0$. Rearranging yields the condition in Proposition 1

The second part of the proposition states that if $d_{t}^{G I}\left(\theta_{i}\right)=1$ for all $i \in\{1, \ldots, N\}$, the utility from full group enrollment is strictly higher than utility from any type of partial enrollment satisfying $I_{t} \in\left[I^{*}, N-1\right]$. We prove this using Jensen's inequality.

In a fully insured group, total group earnings within a loan cycle are $N(e-p h)$; every group member earns $e-p h$ with certainty. In a partially insured group, where $I_{t} \in\left[I^{*}, N-1\right]$, all $I_{t}$ insured group members earn $e-p h$ each, and all $N-I_{t}-F_{t}^{I_{t}}$ healthy uninsured group members earn $e$. The group further contributes $h-e$ for every delinquent by Assumption (A3). As a result, 
total expected earnings within a loan cycle in a partially insured group are:

$$
\begin{aligned}
I_{t}(e-p h)+\left(N-I_{t}-\mathrm{E} F_{t}^{I_{t}}\right) e-\mathrm{E} F_{t}^{I_{t}}(h-e) & =N e-I_{t} p h-\mathrm{E} F^{I_{t}} h \\
& =N e-I_{t} p h-\left(N-I_{t}\right) p h \\
& =N(e-p h)
\end{aligned}
$$

where the expected number of delinquents is $\mathrm{E} F^{I_{t}}=\left(N-I_{t}\right) p$ because $F_{t}$ follows a binomial distribution with $N-I_{t}$ trials. This means that total payoff under partial enrollment is a meanpreserving spread of the joint payoff in the full enrollment case. Given the assumption of concave utility, Jensen's inequality implies that total utility in a fully insured group is strictly higher than total utility in a partially insured group:

$$
\sum_{i}^{N} U\left(e-p h ; \theta_{i}\right) \geq \sum_{i}^{N} \mathrm{E}\left[U\left(Y_{i t} ; \theta_{i}\right) \mid I_{t} \in\left[I^{*}, N-1\right]\right] .
$$

\section{PROOF PROPOSITION2}

Proof If client $i$ believes that all her group members will enroll in the present loan cycle, and enrolls herself as well, total utility from the current and all future loan cycles is:

$$
U\left(e-p h ; \theta_{i}\right)+\beta V_{i, t+1}
$$

An insured individual earns $e$ with certainty, pays the insurance premium $p h$ in the present loan cycle and continues to the next loan cycle.

If she does not enroll, her total expected utility is equal to:

$$
(1-p) U\left(e ; \theta_{i}\right)+\beta V_{i, t+1}
$$

She earns $e$ with probability $1-p$, risks earning 0 with probability $p$ and continues to the next loan cycle with certainty.

The utility difference between enrolling and staying without insurance is:

$$
U\left(e-p h ; \theta_{i}\right)-(1-p) U\left(e ; \theta_{i}\right) \geq 0 \Leftrightarrow \theta_{i} \geq \theta^{*}
$$

by the definition for $\theta^{*}$ in Equation (2). An individual will take insurance if and only if $\theta_{i} \geq \theta^{*}$. 


\section{Predictions for the experimental parameters}

This appendix first shows under which conditions full group enrollment enhances welfare over zero enrollment in the experiment, i.e. predicts demand in the group insurance treatment for high RA versus low RA clients. Second, we analyse under which conditions repeated interactions can induce low RA clients to commit to the social optimum. Because of the repeated nature of the game, clients may threaten free-riders to stay uninsured in future loan cycles themselves. The question is whether such dynamic sanctions prevent free-riding and are equilibrium strategies. Third, we derive predictions for high RA clients if fewer than $N-1$ peers are believed to enroll.

We focus on the first four rounds in which clients only know they will play the game for a large number of rounds. They do not know in which round the game will stop, or that the game will end with probability $1 / 6$ after the fourth round, as determined by the roll of the die. In the experiment, this was not announced until the end of the fourth round. Since participants must have realised that the game would only last for a few hours and could not continue forever, we assume that the period- $t$ discount factor for round $s$ is strictly lower than one for any loan cycle $s>1, \beta_{1, s}<1$. For tractability, we calculate continuation values using exponential discounting, i.e. $\beta_{1, s}=\beta^{s-1}$, so that the continuation values derived in Appendix A are defined by Equation (10) for the scenario with full enrollment in future loan cycles,

$$
V_{i, t+1}(F E)=\frac{\beta}{1-\beta} U\left(10 ; \theta_{i}\right)
$$

and Equation (13) for a scenario with zero enrollment in future loan cycles,

$$
V_{i, t+1}(Z E)=\frac{0.3277 \beta}{1-0.737 \beta}\left(U\left(22.5 ; \theta_{i}\right)+U\left(12.5 ; \theta_{i}\right)\right)
$$

\section{C.1 Is full group enrollment the social optimum in loan cycle $t$ ?}

The insurance decision entails a social dilemma when clients strategically forgo individual insurance even though insurance optimises group welfare and clients are willing to join group insurance. Here, we derive under which conditions a social planner would prefer to enroll the entire group, which is the case if Inequality (4) from the proposition on group insurance, Proposition 1 is satisfied. Given the parameters used in the experiment, we can write Inequality (4) as:

$$
0.2627 V_{i, t+1} \geq 0.3277\left(U\left(22.5 ; \theta_{i}\right)+U\left(12.5 ; \theta_{i}\right)\right)-U\left(10 ; \theta_{i}\right)
$$

where 0.2627 is one minus the continuation probability, $1-P_{0}$, or the probability that an uninsured group defaults; $(4 / 5)^{5}=0.3277$ is the probability that no group member falls ill (so that the client 
contributes zero and consumes 22.5$)$; and $4 *(1-p)^{4} *(1 / 5)=0.3277$ is the probability that participant $i$ and three of the four peers are healthy, while one of the four peers falls ill (so that the client contributes 10 and consumes 12.5).

The condition above holds for every $\theta_{i} \in \Theta$ if it also holds for the lowest degree of risk aversion, which is the limiting case of risk-neutrality. Inserting linear utility, $\lim _{\theta_{i} \downarrow 0} U\left(Y ; \theta_{i}\right)=Y$, Inequality (4) simplifies to:

$$
0.2627 V_{i, t+1} \geq 1.469 \Leftrightarrow V_{i, t+1} \geq 5.591
$$

Suppose that the client believes that all group members, including herself, will always enroll in the future. The continuation value then corresponds to the value from full enrollment, $V_{i, t+1}(F E)$ derived in Appendix A and repeated in Equation (17) above. In that case,

$$
V_{i, t+1}(F E)=\frac{10 \beta}{1-\beta} \geq 5.591 \Leftrightarrow \beta \geq 0.359
$$

Alternatively, suppose the client believes that nobody in the group, including herself, will ever enroll in future loan cycles. The continuation value is then defined by $V_{i, t+1}(Z E)$ in Equation (18), and the client enrolls in the current loan cycle if and only if

$$
V_{i, t+1}(Z E)=\frac{0.3277 * 35 \beta}{1-0.737 \beta}=\frac{11.4688 \beta}{1-0.737 \beta} \geq 5.591 \Leftrightarrow \beta \geq 0.359
$$

Thus, in both scenarios, given a reasonable discount factor $\beta \geq 0.359$, even the least risk averse client is willing to join group insurance, and full group enrollment is the social optimum.

Note, however, that we do not impose this restriction on discount factors. Clients may have assigned a lower value to future loan cycles, and this is precisely one of the reasons for using group insurance as a benchmark for socially optimal demand.

\section{C.2 Credibility and effectiveness of a grim trigger strategy}

The second question is whether the repeated nature of the game enables clients to enforce cooperation when offered individual insurance. Clients face repeated insurance decisions within the same group, and can sanction free-riders by staying uninsured. To analyse whether such sanctions may arise in equilibrium, assume that clients play a dynamic strategy in which insurance status in loan cycle $t, d_{i t}$, depends on past insurance decisions. Specifically, if $d_{i \tau}$ indicates the insurance decision of group member $i \in\{1, \ldots, n\}$ in a past loan cycle $\tau<t$, assume that clients play the 
following grim trigger strategy:

$$
d_{i t}=\min d_{j \tau} \forall j \neq i, \tau \in\{1, \ldots, t-1\}
$$

In words, clients commit to 'Full Enrollment', in which case future discounted utility is $V_{i, t+1}(F E)$, defined in Equation (17). Only if a group member defects and starts free-riding, the group moves to 'Zero Enrollment', in which case future expected discounted utility is $V_{i, t+1}(Z E)$, defined in Equation (18).

The grim trigger strategy represents an equilibrium under the following two conditions. First, dynamic incentives need to be sufficiently strong for this threat to be effective. A client will enroll if and only if the future benefits of full enrollment, $V_{i, t+1}(F E)-V_{i, t+1}(Z E)$, outweigh the one-time benefit of free-riding in a fully insured group, i.e. the difference in expected utility from the current loan cycle without and with insurance:

$$
V_{i, t+1}(F E)-V_{i, t+1}(Z E) \geq \frac{4}{5} U\left(22.5 ; \theta_{i}\right)-U\left(10 ; \theta_{i}\right)
$$

Free-riding individuals in insured groups earn 22.5 with probability $4 / 5$. Insured individuals earn 10 with certainty.

This condition is least likely satisfied in the limiting case of risk-neutrality. Given Equations (10) and (13), and assuming linear utility, the condition above reduces to:

$$
\frac{10 \beta}{1-\beta}-\frac{11.469 \beta}{1-0.737 \beta} \geq 8 \Leftrightarrow \beta \geq 0.79
$$

For any discount factor $\beta \geq 0.79$, the threat of future retaliation is sufficiently strong to commit free-riders to the social optimum, independent of the level of risk aversion $\theta_{i} \in \Theta$.

Second, the threat of staying uninsured needs to be credible. In other words, clients should have no incentive to enroll if their peers do not enroll either, i.e. zero enrollment. This precludes the existence of 'always-takers' who prefer to have insurance even if no other group member is ever insured. A client will enroll in an otherwise uninsured group if and only if insurance optimises utility. Since this is most likely satisfied for clients with the highest level of risk aversion, we consider the limiting case of a client with Leontief preferences, normalizing utility to $\lim _{\theta_{i} \uparrow \infty} U\left(Y ; \theta_{i}\right)=1$ for all $Y>0$ and $\lim _{\theta_{i} \uparrow \infty} U\left(0 ; \theta_{i}\right)=0$. These clients are indifferent between any strictly positive level of consumption, making them infinitely risk averse.

We first derive total expected utility if the client decides not to enroll. Using Equation (18), which defines the continuation value from zero enrollment, and $U\left(Y ; \theta_{i}\right)=1$ for all $Y>0$, total 
expected utility if the client stays uninsured is:

$$
\left(\frac{4}{5}\right)^{5}\left(U\left(22.5 \theta_{i}\right)+U\left(12.5 ; \theta_{i}\right)\right)+P_{0} V_{i, t+1}(Z E)=\frac{0.656}{1-0.737 \beta}
$$

Every loan cycle, an infinitely risk averse client's expected utility within that loan cycle is 0.656 , and the group continues to the next loan cycle with probability 0.737 .

If the client takes insurance in the otherwise uninsured group, total expected utility is:

$$
\left(\frac{4}{5}\right)^{4} U\left(10 ; \theta_{i}\right)+P_{1} V_{i, t+1}(Z E)=0.410+\frac{0.537 \beta}{1-0.737 \beta}
$$

The first term represents expected utility from the current loan cycle. The client can always repay her own loan and earns 10 before contributing for delinquent peers. With probability $(4 / 5)^{4}=$ 0.4096 , all four peers repay as well. With probability $1-(4 / 5)^{4}$, at least one peer cannot repay, the client contributes 10 , and consumes zero. The second term represents total discounted expected utility from future loan cycles. With probability $P_{1}=(4 / 5)^{4}+4 *(4 / 5)^{3} *(1 / 5)=0.8192$, at most one of the four potential delinquents falls ill, and the group continues to the next loan cycle.

Combining the two equations above, the client decides to enroll if and only if this optimises total expected utility:

$$
\begin{aligned}
\frac{0.656-0.537 \beta}{1-0.737 \beta} & \leq 0.410 \Leftrightarrow \\
0.656-0.537 \beta & \leq 0.410(1-0.737 \beta) \Leftrightarrow \\
0.246 & \leq(0.537-0.302) \beta \Leftrightarrow \\
\beta & \geq 1.046
\end{aligned}
$$

which can never be satisfied since $\beta<1$. Thus, even the infinitely risk averse client would not enroll in an otherwise uninsured group.

Note that the client's expected utility within a loan cycle is lower with than without insurance when all peers are uninsured. Although insured clients are less likely to incur own health expenses, they are also more likely to contribute for ill peers. In that case, a client pays both the insurance premium and contributes for ill peers, substantially reducing the benefits of taking insurances. The main benefit of insurance is an increase in the probability that the group does not default and continues to the next loan cycle, from 0.737 to 0.819 in this case.

In sum, under individual insurance, there is a dynamic equilibrium strategy in which clients enroll if and only if all group members have enrolled in the past, i.e. a grim trigger strategy. This strategy prevents free-riding even among the least risk averse clients if they sufficiently value 
utility from future loan cycles, $\beta \geq 0.79$. Further, the grim trigger strategy is a credible threat even among the most risk averse clients, who will not enroll in an otherwise uninsured group because they prefer avoiding the situation in which they both pay the premium and contribute for delinquent peers.

\section{C.3 Best response to partial enrollment}

Finally, we predict individual insurance decisions for clients who believe that some but not all peers will enroll. Proposition 2 already derived predictions for the case in which clients believe that all peers will enroll $\left(d_{t}^{I I}\left(\theta_{i}\right)=1 \Leftrightarrow \theta_{i} \geq \theta^{*}\right)$, and the previous section predicts zero enrollment among clients who believe none of their peers will enroll. This section analyses the best response for clients with alternative beliefs. For tractability, we assume that client $i$ 's insurance decision in loan cycle $t$ will not influence peers' decisions in loan cycles $s>t$, so that the continuation value $V_{i, t+1}$ does not depend on past behavior, unlike in the previous section.

Define $Z_{i t}$ as the number of peers that client $i$ believes not to take insurance, $Z_{i t}=N-1-\left(I_{t}-\right.$ $d_{i t}$ ). Given that a group consists of five members in the experiment, partial enrollment among peers implies that the number of uninsured peers is restricted to $Z_{t} \in\{1,2,3\}$. For a client who believes that $N-1-Z_{t}$ peers will take insurance, the best response is to enroll if and only if insurance optimises expected utility from the current and future loan cycles. We will analyse under which conditions this condition is satisfied.

Note that in the current loan cycle, expected utility for an insured client is equal to:

$$
\left(\frac{4}{5}\right)^{Z_{i t}} U\left(10 ; \theta_{i}\right)
$$

The insured participant earns 10 if she has no delinquent peers. Since the client has $Z_{i t}$ uninsured peers and is insured herself, this occurs with probability $(4 / 5)^{Z_{i t}}$. If there is at least one delinquent, the insured participant contributes $c_{i t}=10$, yielding zero consumption and zero utility.

For an uninsured client, expected utility in the current loan cycle equals:

$$
\left(\frac{4}{5}\right)^{Z_{i t}}\left(\frac{4}{5} U\left(22.5 ; \theta_{i}\right)+\frac{Z_{i t}}{5} U\left(12.5 ; \theta_{i}\right)\right)
$$

With probability $(4 / 5) *(4 / 5)^{Z_{i t}}$, the client is healthy, has no delinquent peers, and consumes 22.5. With probability $(4 / 5) * Z_{i t} / 5 *(4 / 5)^{Z_{i t}-1}$, the client is healthy, has one delinquent peer, and consumes 12.5. Under alternative outcomes, the participant is ill herself, or the group defaults. In those cases, consumption is zero.

Combined, these two equations yield the difference in expected utility from the current loan 
cycle between uninsured and insured clients:

$$
\left(\frac{4}{5}\right)^{Z_{i t}}\left(\frac{4}{5} U\left(22.5 ; \theta_{i}\right)+\frac{Z_{i t}}{5} U\left(12.5 ; \theta_{i}\right)-U\left(10 ; \theta_{i}\right)\right)
$$

Insurance will also affect expected utility from future loan cycles. Insurance reduces the probability that the group defaults and therefore increases future expected utility. If the client takes insurance, the group continues with probability $(4 / 5)^{Z_{i t}}\left(1+Z_{i t} / 4\right)$. That is, the group continues either if all uninsured group members are healthy, which occurs with probability $(4 / 5)^{Z_{i t}}$, or if one uninsured group member is ill, which occurs with probability $Z_{i t} *(4 / 5)^{Z_{i t}-1} *(1 / 5)=(4 / 5)^{Z_{i t}} * Z_{i t} / 4$. If the client does not take insurance, the group continues with probability $(4 / 5)^{Z_{i t}}\left(4+Z_{i t}+1\right) / 5=$ $(4 / 5)^{Z_{i i}}\left(1+Z_{i t} / 5\right)$, since all uninsured group members are healthy with probability $(4 / 5)^{Z_{i t}+1}=$ $(4 / 5)^{Z_{i t}} *(4 / 5)$, and one uninsured group member is ill with probability $\left(Z_{i t}+1\right) *(4 / 5)^{Z_{i t}} *(1 / 5)$.

Thus, the difference in future expected utility with and without insurance is:

$$
\left(\frac{4}{5}\right)^{Z_{i t}}\left(\frac{4+Z_{i t}}{4}-\frac{5+Z_{i t}}{5}\right) V_{i, t+1}=\left(\frac{4}{5}\right)^{Z_{i t}} \frac{Z_{i t}}{20} V_{i, t+1}
$$

Combining the future benefits of enrolling in insurance in Equation (21) with the current utility losses associated with enrolling in insurance in Equation 20, a client enrolls if and only if:

$$
V_{i, t+1} \geq 4 U\left(12.5 ; \theta_{i}\right)+\left(\frac{4}{5} U\left(22.5 ; \theta_{i}\right)-U\left(10 ; \theta_{i}\right)\right) \frac{20}{Z_{i t}}
$$

Conditional on having zero delinquent peers, which occurs with probability $(4 / 5)^{Z_{i t}}$, the client enrolls if and only if the future benefits of insurance outweigh the costs in terms of current utility. The condition above reveals a key insight. By Definition [2], the second term on the right-hand side is positive if and only if a client has low risk aversion, $\theta_{i}<\theta^{*}$. For them, the derivative in the number of uninsured peers, $Z_{i t}$, is negative. Hence, as more peers stay out of insurance, Condition 22] is satisfied at lower levels of $V_{i, t+1}$. For high RA clients, on the other hand, the derivative in $Z_{i t}$ is positive. As a high RA client believes that more peers will not enroll, her continuation value needs to be higher in order to be willing to enroll. 


\section{Experimental script}

This appendix provides the most important elements of the instructions back-translated from Kiswahili.

\section{Game 1: Individual liability and individual insurance}

Introduction The game starts as follows: You are one of five members of a microcredit group. Assume that you are borrowing 40,000 Shillings from a bank every month for your business to make a profit. Your profit is 22,500 Shillings. If you are able to repay the loan, you will repay it. In that case you can borrow a second time so then you will play this game twice. If you do not repay the loan you will, you will not be able to play again.

Health problems Before you repay your loan, two things may happen: you may get sick or you may not. If you are healthy, you will be able to repay the 40,000 shilling debt to the bank. A research assistant will put a profit of 22,500 shillings in your piggybank. Since you repay your loan, the bank is allowing you to borrow again.

But if you are sick, you will need to use your full income on treatment. Therefore, you pay a research assistant your 62,500 shillings and your profit will be 0 . It means that you will not be able to repay the loan. The bank will not lend you money again and hence you will not be able to play this game again. You will be able to borrow again from the bank and get money again only when a new game starts. It is important that you know you will not be able to open the piggybank when the game is in play. Therefore, you cannot use the money from the piggybank to repay your debt.

To know if you are sick or not, the research assistant will tell you to take a card from an envelope. There are 5 cards in the envelope. Four (4) of the cards have no writings on them and one card has a picture of a doctor. If you get the card with a picture, you are sick. You are supposed to take a card while you are not looking at it. After you get the card, look at it and then put it back into the envelope. Another person should do the same so that every person has the same chance to be sick.

Health insurance You can get a health insurance policy every time you play this game. It costs 12,500 shillings. With health insurance you will not be required to pay for medical expenses if you get sick. Therefore you will be able to repay the bank loan of 40,000 shillings. Your profit is always 10,000 shillings. The research assistant will put this profit in the piggybank. The bank will allow you to borrow again.

If you do not have health insurance, you will not pay 12,500 shillings for the insurance policy. If you are not sick, you will pay the loan and your profit will be 22,500 shillings. If you are sick, 
you will loose all your income and you will not be able to repay the loan, your profit will be 0 and you will not play in this round again. You will only be able to borrow from the bank again and get money in a new game.

The insurance will be used only for one round. You can decide if you want to pay for the health insurance policy or not in every round of the game. A test game was played in public.

The group score board The research assistant will show you whether your group members managed to pay or not. The research assistant will do this after every round. Every member in your group is represented by a symbol: square, moon, circle, triangle and a star. The research assistant will put the symbol on the board.

A group member's profit is 22,500 shillings if the member did not pay for health insurance and is not sick in this round. A group member's profit is 0 shillings and he or she will not continue to play the game in future rounds if the member did not pay for health insurance and is sick. A group member's profit is 10,000 shillings if the member paid for health insurance and either got sick or not. All members who are on the green line can pay and hence can continue to play the game in future rounds. All group members who are on the red line cannot repay and will not continue to play the game.

Please remember that you can not talk to anybody when the game is in play. Your group members do not know your symbol and hence are unaware of your decisions.

From this point onward, the plastic money you will win will be converted to real money. You will get paid in cash the money in the piggybank at the end of this game. You will get paid 1,000 shillings in real money for every 10,000 shillings in plastic money in the bank.

\section{Game 2: Joint liability and group insurance ${ }^{26}$}

The second game looks like the first one. The cost of health insurance is 12,500 shillings. The difference with the first game is that the decision on enrolling in health insurance must be made by the whole group, not individually. The other difference is that now the loan from the bank is taken as a group and the loan is to be paid by the whole group in full. The bank will only allow the group to borrow again if the group will repay the entire loan. The game will be over for the whole group if the group fails to repay the full loan.

So first, in this game, you vote to decide if you want the group to have a health insurance policy or not. The policy will be paid if the whole group votes in favor of health insurance. If at least one member of the group votes not to get insurance, the whole group will go without insurance and you will not pay the premium. You will vote on this card saying whether you want

\footnotetext{
${ }^{26}$ Instructions for individual insurance treatments are similar to the instructions for group insurance but exclude the information on unanimity voting. Available upon request.
} 
to get the policy or not. Circle the symbol on the left marked with a cross if you want to buy the policy. Circle the symbol on the right marked with a cross with a line passing through it if you do not want to pay for the insurance policy.

The other difference with the previous game is that now the whole group is required to pay the loan in full and together. Therefore, those who cannot cover their share of the loan should get assistance from their fellow group members. How much assistance will be required depends on how many group members fail to repay their share of the loan.

If all five members of the group can repay their loan, each member will pay 40,000 shillings. All five members of the group will advance to the next round. If four group members can repay their loan and one fails, each of those four will repay their loan of 40,000 shillings and will assist the one who failed with 10,000 shillings each. All group members will advance to the next round including the one who failed to meet his or her responsibility. If less than four people can repay their share, meaning that two or more group members fail to repay, then the group will not be able to repay in full. The game will end for all group members. Those who are able to repay their 40,000 shilling loan do so and spend the rest of their profits to help defaulting group members. Their final profit in this round is 0 . Thus, each group is required to have four or more members who can repay to advance to the next round of the game.

Treatments without communication Please remember that you can not talk to anybody when the game is in play. Your group members do not know your symbol and hence are unaware of your decisions.

Treatments with communication Please remember that it is not allowed to communicate with anyone during the game. But before each round begins, you are allowed to communicate with your fellow credit group members about the insurance policy. You may communicate with them for two minutes. Communication will not be allowed after these two minutes. Your group members do not know your symbol and hence are unaware of your decisions.

Number of rounds in the game We will play this game for several rounds. We are not certain how many rounds. If you do not drop out of the game, you will be able to play at least four times. From the fourth round onwards, we will toss a die after every round. The game will continue if the die lands at number $2,3,4,5$ or 6 . The game will stop for everybody in the group if the die settles on number 1 . 


\section{E Appendix Tables}

Table A1: Willingness to join insurance in Round 1 - All coefficients

\begin{tabular}{|c|c|c|c|c|}
\hline & \multicolumn{2}{|c|}{ High RA participants } & \multicolumn{2}{|c|}{ Low RA participants } \\
\hline & (2) & (4) & (6) & (8) \\
\hline Individual & $\begin{array}{l}-0.031 \\
(0.030)\end{array}$ & $\begin{array}{c}-0.023 \\
(0.044)\end{array}$ & $\begin{array}{l}-0.300 \\
(0.096)\end{array}$ & $\begin{array}{l}-0.111 \\
(0.142)\end{array}$ \\
\hline$p$-value & 0.206 & 0.214 & $0.017^{* *}$ & 0.165 \\
\hline Nr. Low RA peers & $\begin{array}{l}-0.035 \\
(0.016)\end{array}$ & $\begin{array}{c}-0.032 \\
(0.020)\end{array}$ & $\begin{array}{c}0.053 \\
(0.043)\end{array}$ & $\begin{array}{c}0.098 \\
(0.050)\end{array}$ \\
\hline$p$-value & $0.077^{*}$ & 0.133 & 0.183 & $0.043^{* *}$ \\
\hline Individual x Nr. Low RA peers & & $\begin{array}{l}-0.008 \\
(0.033)\end{array}$ & & $\begin{array}{l}-0.168 \\
(0.094)\end{array}$ \\
\hline$p$-value & & 0.447 & & 0.117 \\
\hline Membership years & $\begin{array}{c}0.016 \\
(0.009)\end{array}$ & $\begin{array}{c}0.016 \\
(0.009)\end{array}$ & $\begin{array}{l}-0.094 \\
(0.037)\end{array}$ & $\begin{array}{l}-0.082 \\
(0.038)\end{array}$ \\
\hline$p$-value & $0.010^{* *}$ & $0.010^{* *}$ & $0.041^{* *}$ & $0.033^{* *}$ \\
\hline Has outstanding loan & $\begin{array}{c}-0.074 \\
(0.051)\end{array}$ & $\begin{array}{c}-0.075 \\
(0.051)\end{array}$ & $\begin{array}{l}-0.089 \\
(0.121)\end{array}$ & $\begin{array}{l}-0.071 \\
(0.120)\end{array}$ \\
\hline$p$-value & $0.018^{* *}$ & $0.018^{* *}$ & 0.205 & 0.261 \\
\hline With real credit group member & $\begin{array}{c}0.019 \\
(0.031)\end{array}$ & $\begin{array}{c}0.018 \\
(0.031)\end{array}$ & $\begin{array}{l}-0.132 \\
(0.090)\end{array}$ & $\begin{array}{l}-0.142 \\
(0.089)\end{array}$ \\
\hline$p$-value & 0.290 & 0.281 & $0.084^{*}$ & $0.063^{*}$ \\
\hline Prop. ill rounds in first game & 0.021 & 0.021 & 0.432 & 0.478 \\
\hline & 0.078 & 0.079 & 0.186 & 0.185 \\
\hline$p$-value & 0.399 & 0.397 & $0.052^{*}$ & $0.045^{* *}$ \\
\hline R-squared & 0.044 & 0.044 & 0.292 & 0.318 \\
\hline Mean Group Ins & 0.954 & 0.954 & 0.852 & 0.852 \\
\hline Observations & 264 & 264 & 91 & 91 \\
\hline
\end{tabular}




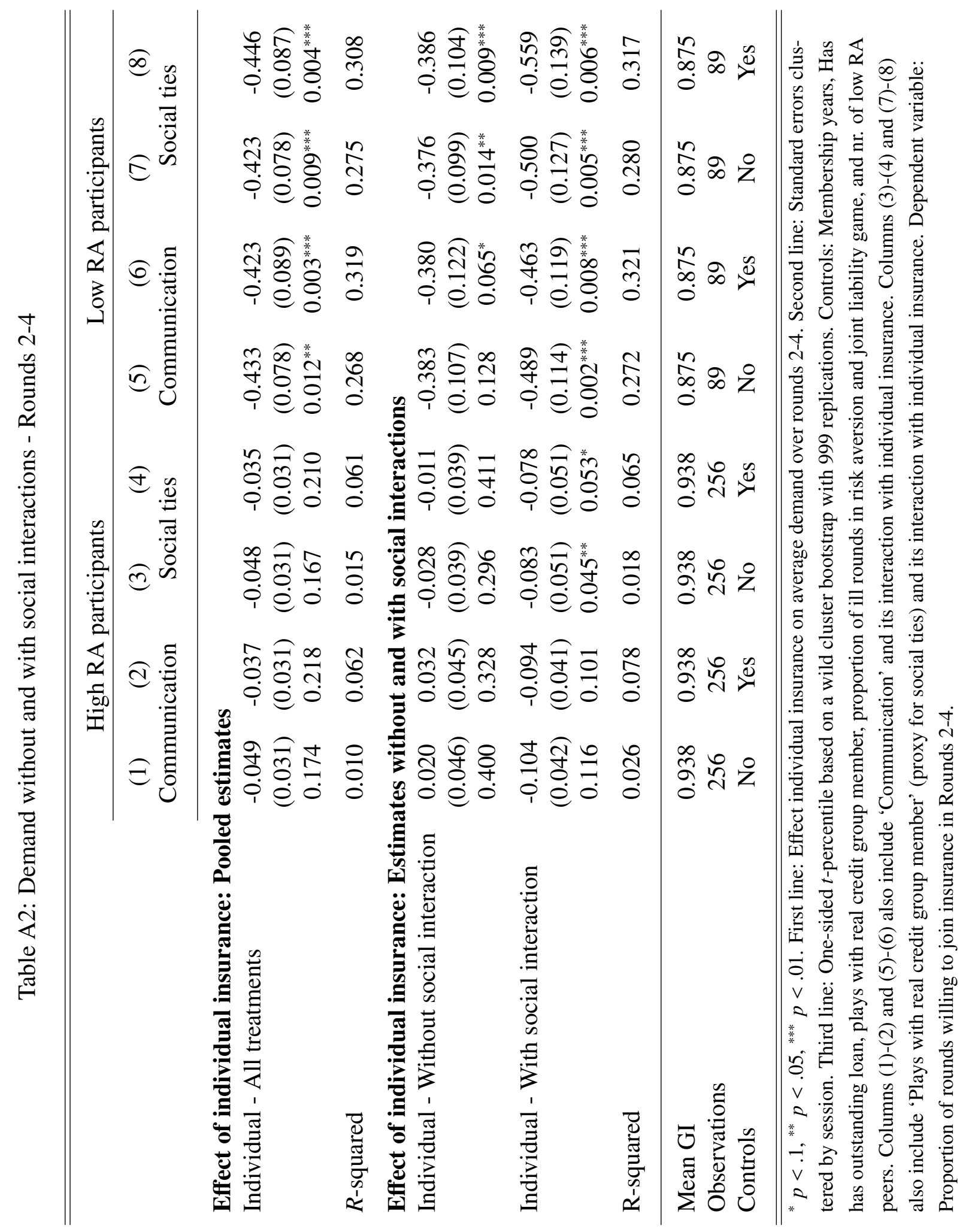




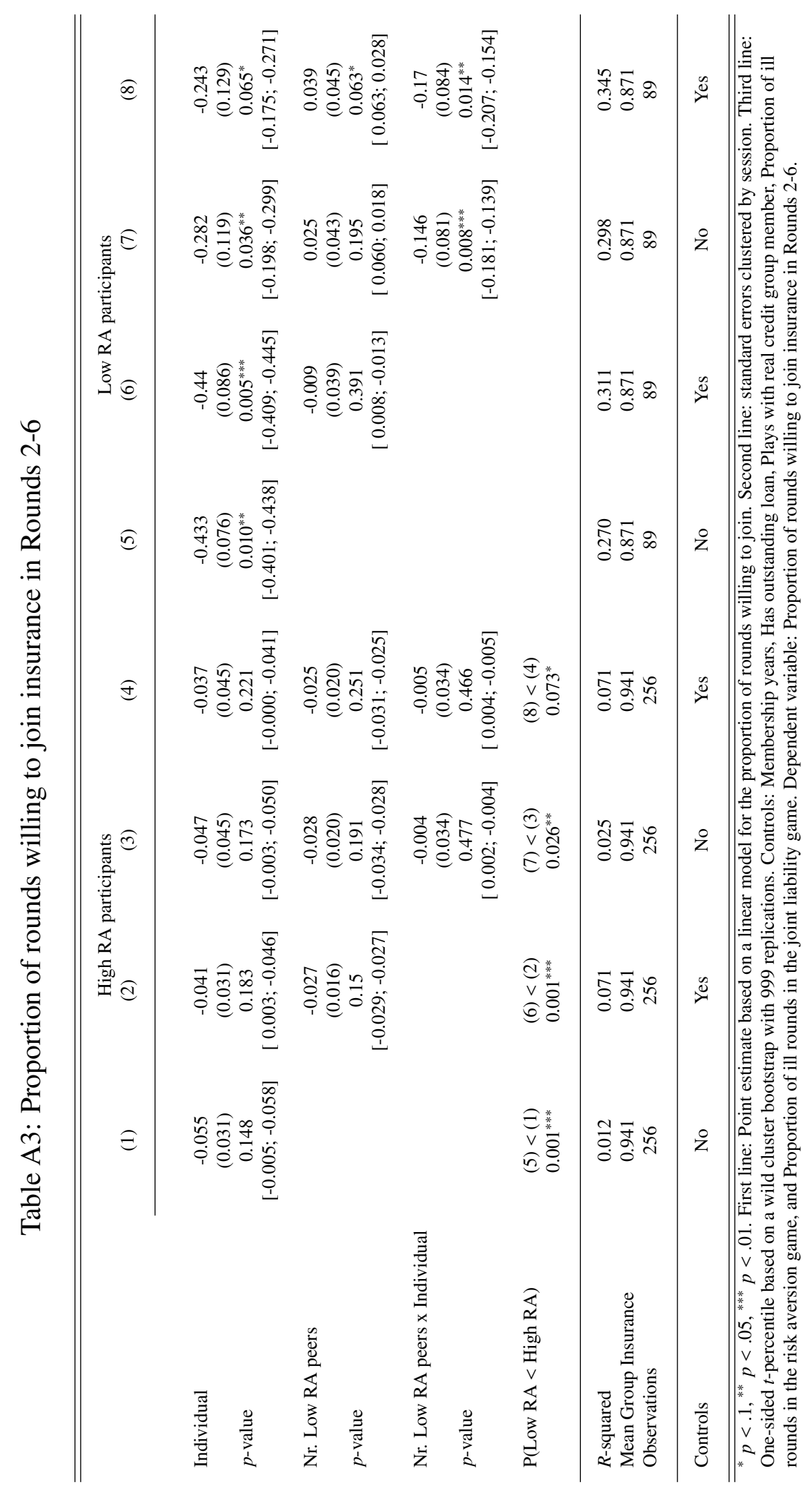


Table A4: Correlations participant characteristics and demand for insurance

High RA participants Low RA participants

Correlation $p$-value Correlation $p$-value

(1)

(2)

(3)

(4)

A. Demographic and socio-economic characteristics

Female

0.05

0.548

$-0.03 \quad 0.844$

Married

$-0.06$

0.218

$-0.07$

0.552

Age

$-0.02$

0.796

$-0.08$

0.244

Household size

0.03

0.680

0.17

0.172

Years of education

0.01

0.806

$-0.04$

0.666

Log of per capita $\mathrm{HH}$ income

$-0.02$

0.750

$-0.03$

0.782

\section{B. Health characteristics}

Visited provider

$-0.03$

0.602

$-0.02$

0.806

Other visited provider

Log HH health exp

0.12

$0.068^{*}$

0.01

0.968

0.05

0.576

0.12

0.354

Nr. times foregone care

0.06

0.210

0.08

0.374

Knows health insurance

$-0.12$

0.124

$-0.00$

0.940

Has health insurance

$-0.09$

0.460

$-0.14$

0.254

C. Microcredit variables

Log of business profit (TSH)

0.06

0.476

0.03

0.848

Membership years

0.11

$0.016^{* *}$

$-0.21$

0.120

Has outstanding loan

Log of last loan (TSH)

$-0.08$

$0.008^{* * *}$

$-0.04$

0.656

$-0.01$

0.904

0.09

0.444

Delinquent in group

$-0.03$

0.538

$-0.11$

0.298

Contributed for peer

0.01

0.904

$-0.05$

0.556

Has been delinquent

0.00

0.983

0.07

0.486

Peers contributed

$-0.00$

0.996

0.12

0.130

\section{Game-related variables}

Nr. real credit group

0.00

0.970

$-0.23$

$0.064^{*}$

Prop. ill rounds in first game

0.05

0.368

0.25

$0.066^{*}$

${ }^{*} p<.1,{ }^{* *} p<.05,{ }^{* * *} p<.01 . p$-value: Two-sided $t$-percentile, based on a wild cluster bootstrap with 999 replications. Dependent variable: willingness to join insurance in the first round. High (Low) RA: High (Low) risk aversion. 